\title{
The Multifaceted Reactivity of Single-Atom Heterogeneous Catalysts
}

\section{Review Article}

Author(s):

Mitchell, Sharon; Vorobyeva, Evgeniya; Pérez-Ramírez, Javier

Publication date:

2018-11-19

Permanent link:

https://doi.org/10.3929/ethz-b-000304150

Rights / license:

In Copyright - Non-Commercial Use Permitted

Originally published in:

Angewandte Chemie. International Edition 57(47), https://doi.org/10.1002/anie.201806936

\section{Funding acknowledgement:}

169679 - Doing more with less: efficient single-atom catalysts based on carbon nitride for sustainable chemical transformations (SNF) 


\section{Reactivity of Single-Atom Heterogeneous Catalysts: Unique and Multifaceted}

Sharon Mitchell, ${ }^{*}$ Evgeniya Vorobyeva, and Javier Pérez-Ramírez*

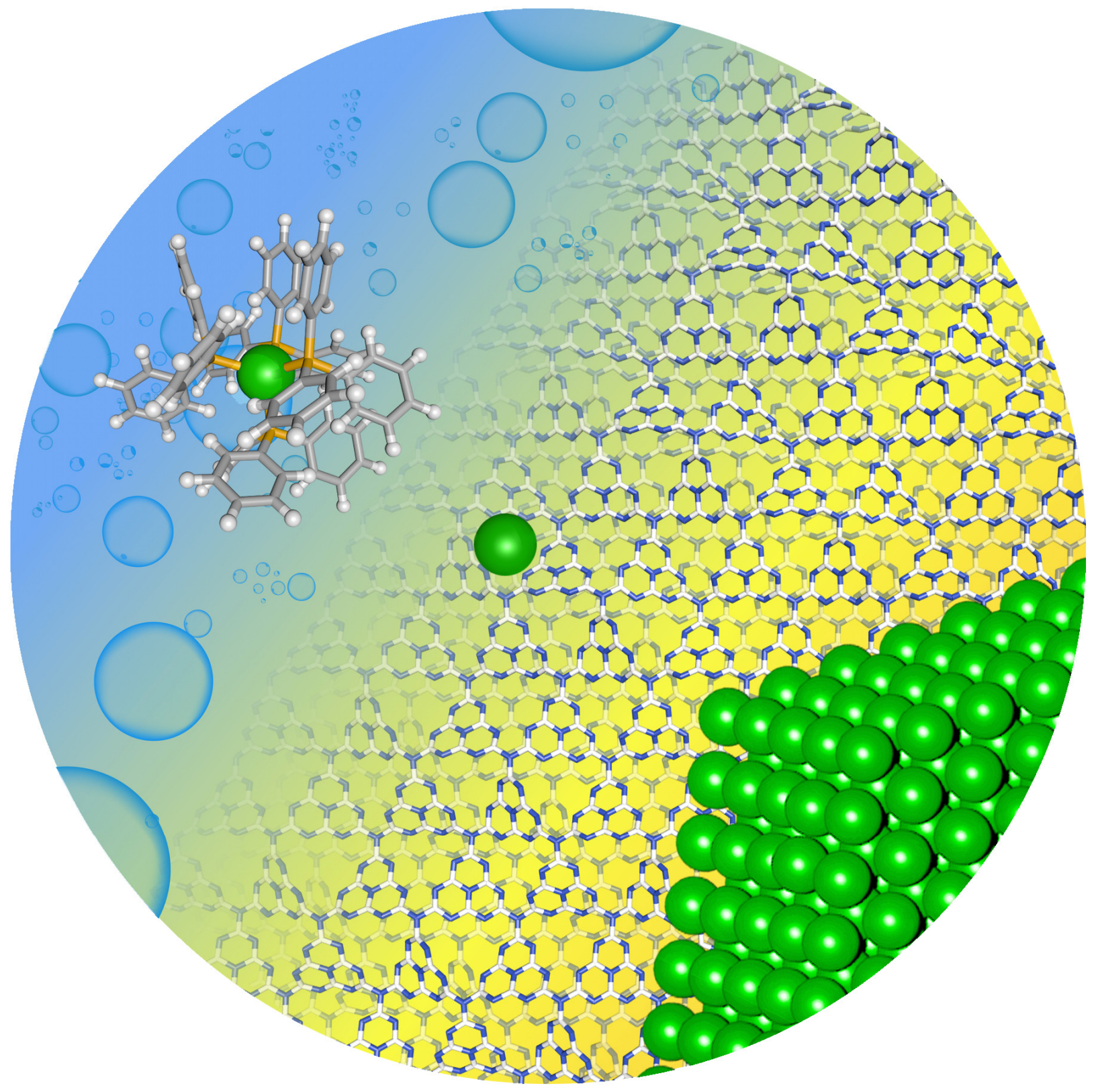


Abstract: Single-atom heterogeneous catalysts (SACs) attached to carefully chosen hosts, are attracting considerable interest, principally because they offer maximal reactivity per metal atom and are usually readily recyclable. But the diminution of the atomic population of nanoparticles or nanoclusters to single atoms can significantly alter reactivity owing to consequent changes in the active site structure. By examining various, diverse applications, we ascertain whether the performance of SACS is enhanced or depressed. We also note that SACs generally display unique kinds of catalytic cycles. The choice of host is crucial, since it influences both the electronic and steric environment of the metal center. Moreover, it may function as a co-catalyst. All these aspects impact upon the design of new SACs, which exhibit similarities between hetero and homogeneous predecessors. In addition, SACs offer a viable replacement of soluble metal complexes in processes that remain difficult to heterogenize.

\section{Introduction}

The ability to develop high performance catalysts is fundamental to the innovation required to meet the sustainability goals of modern society. ${ }^{[1]} A$ universal design principle is the synthesis and assembly of molecules and/or materials integrating active sites with optimized geometric and electronic properties. Catalysts can be divided into two general types, those that work in a different phase from the reactants (heterogeneous catalysts) and those that are used in the same phase (homogeneous catalysts). Because they typically operate via different mechanisms, two distinct branches of catalysis have evolved independently. Heterogeneous catalysts are widely favored by industry for their easy recovery and robustness. Interestingly, although the function of catalysts has long been known to be surface driven, ${ }^{[2]}$ most major advances in supported metal systems still refer to the use of nanoparticles (NPs). Even when small, ${ }^{[3]}$ the dispersion ( $D=$ number of surface atoms/total number of atoms) can be low (around $20 \%$ for a $4 \mathrm{~nm}$ particle) with a large fraction of frustrated bulk atoms.

An innovative area of research, is the development of singleatom heterogeneous catalysts (SACs), nanostructured solids that integrate spatially-isolated metal atoms on appropriate host matrices (Fig. 1).$^{[4,5]}$ At the maximum limit of metal dispersion, these pioneering materials generate great interest due to the potential for every atom to contribute to catalytic turnover in a targeted application. At the same time, the increased active site uniformity and closer structural resemblance has led several authors to postulate that SACs may be able to mimic the desirable highly specific selectivity of homogeneous catalysts, the use of which still dominates in many fine chemical

[a] Dr. S. Mitchell, E. Vorobyeva, Prof. J. Pérez-Ramírez ETH Zurich, Department of Chemistry and Applied Biosciences, Institute for Chemical and Bioengineering, Vladimir-Prelog-Weg 1, 8093 Zurich, Switzerland

E-mails: msharon@chem.ethz.ch; jpr@chem.ethz.ch

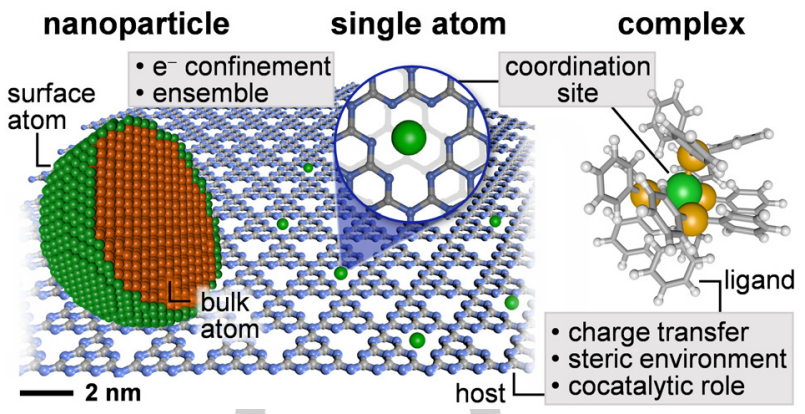

Figure 1. Structural features of metal catalysts based on supported NPs or SAs, or soluble complexes that originate active sites with distinct properties (grey boxes).

applications. ${ }^{[6]}$ The alternative heterogenization of these soluble metal complexes, primarily by grafting or encapsulating them onto suitable supports, has met with marginal success. Loss of structural flexibility upon immobilization, reduced accessibility, and instability due to metal leaching have all been cited for the inferior performance. ${ }^{[7]}$ SACs differ from these anchored complexes because they minimize the use of labile and often unstable ligands, with the metal fully or partially coordinating to immobile hosts.

The design of an SAC can be expected to require the harmonization of multiple attributes such as high stability to sintering or metal loss, the presence of sufficient and uniform active sites, well-tailored electronic and geometric structure, and scalability. To meet the goals of improving metal utilization in heterogeneously-catalyzed processes or replacing homogeneous systems it is imperative to understand how the properties of SACs compare to catalysts based on supported NPs or soluble complexes (Fig. 1), and how this affects their reactivity. Exploring the distinct catalytic behavior of supported metal catalysts of different size, Liu et al. recently highlighted the need for improved structure-performance relations over SACs ${ }^{\left[{ }^{[8]}\right.}$ Wang et al. also touched upon this question in a review on developments in the field of SACs. ${ }^{[9]}$

To provide a complementary perspective, in this minireview we begin by concisely analyzing the key structural and electronic characteristics of SACs. Subsequently we explore their reactivity in diverse, prominent applications identifying when they display better or worse performance with respect to traditional heterogeneous and homogeneous analogues. In each case, the link between the observed changes in the catalytic cycle and property distinctions is examined.

\section{Properties of SACs}

One of the first challenges in the development of SACs was how to stabilize metal atoms against sintering or leaching in sufficient amounts to give appreciable activity. Metal-containing zeolites and zeotypes, in which metal centers were mainly isolated in crystallographic positions, were among the most notable early 

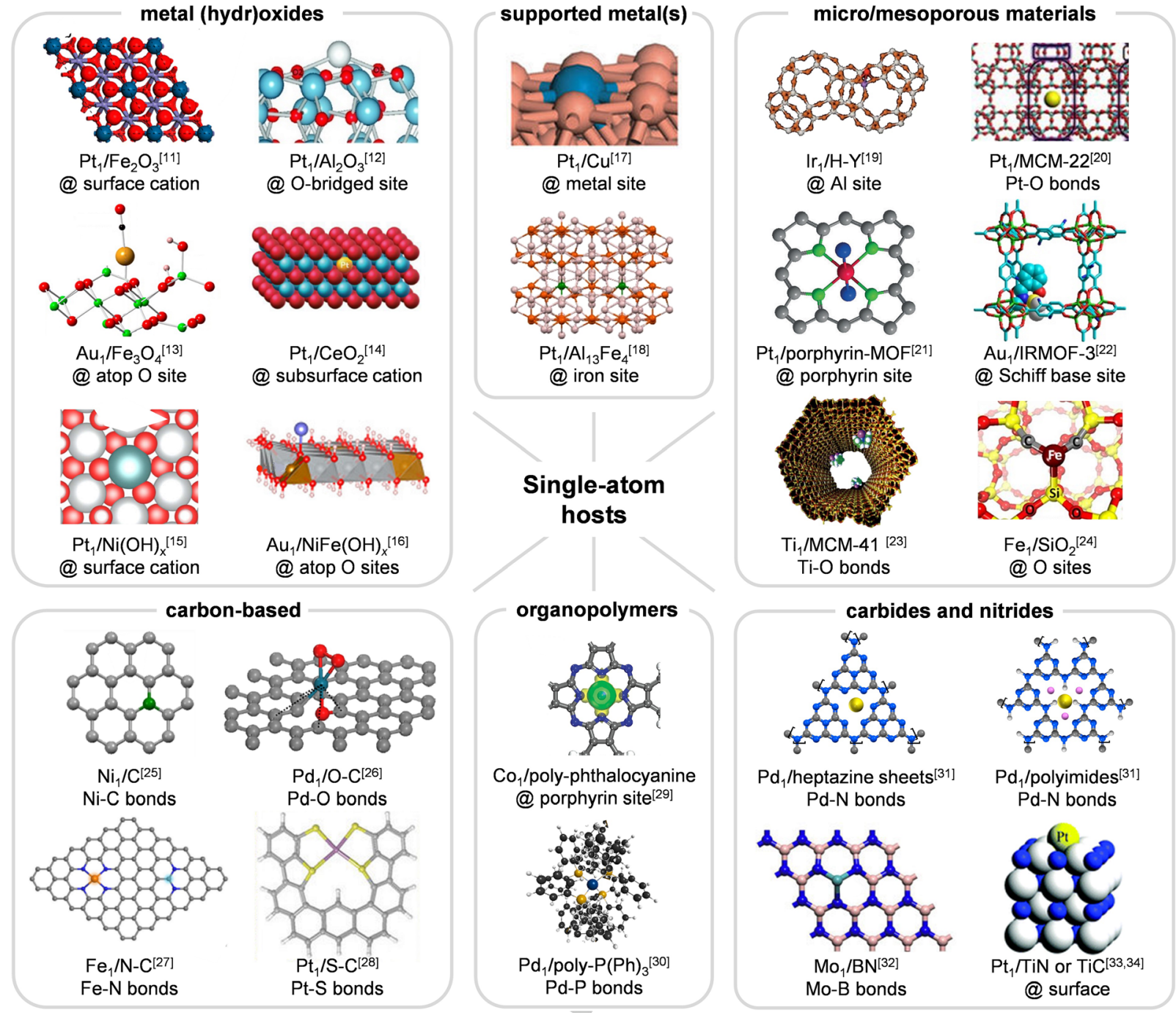

organopolymers

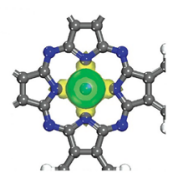

$\mathrm{Co}_{1} /$ poly-phthalocyanine @ porphyrin site ${ }^{[29]}$

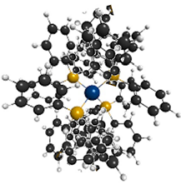

$\mathrm{Pd}_{1} /$ poly- $\mathrm{P}(\mathrm{Ph})_{3}{ }^{[30]}$ Pd-P bonds

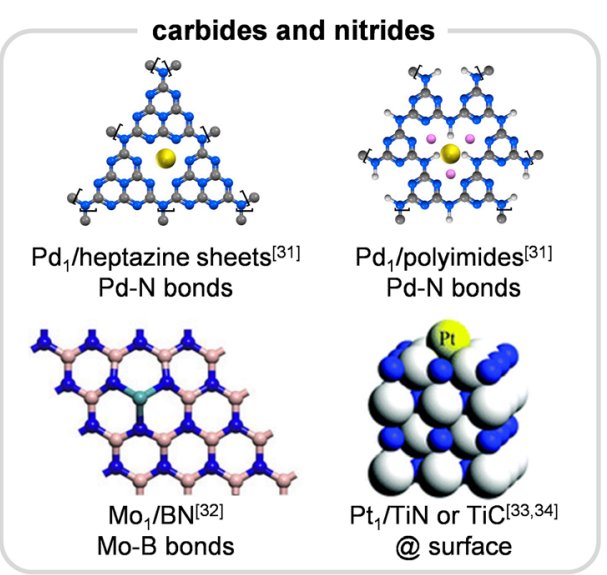

Figure 2. Diverse host materials that have been studied to prepare SACs. Representative examples illustrate the distinct reported metal coordination sites. The significantly different structures are expected to have a decisive impact on the performance, as elaborated in this review.

examples of successful SACs. ${ }^{[10]}$ Aided by synthetic and analytical advancements, a huge range of potential host materials has now been reported (Fig. 2), encompassing metal oxides, ${ }^{[11-14]}$ metal hydroxides, ${ }^{[15,16]}$ metals (also termed singleatom alloys, SAAs), ${ }^{[17,18]} \mathrm{micro} / \mathrm{mes}$ oporous materials like zeolites, $^{[19,20]}$ metal organic frameworks, ${ }^{[21,22]}$ and silicas, ${ }^{[23,24]}$ carbon-based, ${ }^{[25-28]}$ organopolymers, ${ }^{[29,30]}$ nitrides, ${ }^{[31-33]}$ and carbides. ${ }^{[34]}$ Further extending the diversity of this framework, host functionalization strategies, for example through the partial surface hydration, ${ }^{[35]}$ introduction of alkali metals, ${ }^{[36]}$ or decoration with ethylene glycolate species, ${ }^{[37]}$ have also been successfully demonstrated to enhance the anchoring of metal atoms.

Significant differences in the possible binding sites can be envisaged depending on the type of host, and consequently in the type of bonding, coordination number, and steric environment (i.e., the three-dimensional surroundings) of metal centers. Metal (hydr)oxides exist in a wide variety of geometric arrangements and crystal forms and may exhibit anionic or cationic vacancies forming phases of distinct stoichiometry. Various preferred coordination sites have been predicted for this class of host, mostly associated with the substitution at specific crystallographic positions. Although this structural diversity presents an analytical challenge, it offers significant tunability of the active site, as recently highlighted for $\mathrm{Pt}_{1} / \mathrm{CeO}_{2}{ }^{[14]}$ In comparison, SAAs are characterized by two features, the more active metal is present in low concentrations, and atoms of this metal are thermodynamically more stable when surrounded by the host. ${ }^{[38]}$ Most reported systems comprise substitutional alloys, reflecting the similarity in the atomic radii. For practical application, SAAs are also supported, and thus may present different inequivalent atoms depending on both the relative 


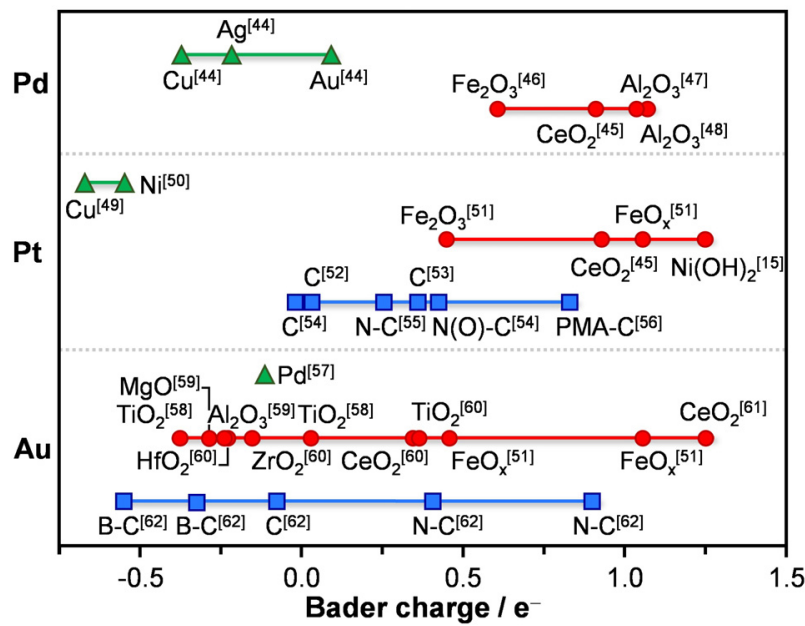

Figure 3. Predicted Bader charges of $\mathrm{Pd}, \mathrm{Pt}$, or $\mathrm{Au}$ atoms on various metal (green triangles), metal oxide (red circles), or carbon-based (blue squares) hosts. Multiple values for the same host correspond to distinct coordination sites.

metal concentration and the size and morphology of the NPs. ${ }^{[39]}$ Furthermore, it is known that the active metal can go into sites beneath the top-most layer (subsurface), ${ }^{[40]}$ becoming similarly inaccessible as bulk atoms in NPs. In carbon-based hosts and related materials, the most favorable coordination sites are usually heteroatoms $(\mathrm{N}, \mathrm{O}, \mathrm{S}$, or $\mathrm{P}) .^{[26-32]}$ The high level of control over the heteroatom content (e.g., nitrogen can be varied from 0-60 wt\%) originates immense scope for tuning the density and structure of the coordination sites within functionalized carbons. ${ }^{[41]}$ There is some indication that metals can become encapsulated in the bulk of carbon-based supports, which may also lead to reduced specific activity. ${ }^{[42]}$

The choice of host can be expected to have a major impact on the electronic characteristics of the metal. Quantum size effects, due to electron confinement in the absence of neighboring atoms with similar energy orbitals (most non-metals), will be accompanied by a shift from continuous energy bands to discrete atomic orbitals. ${ }^{[43]}$ In addition, the strong interaction with the host required for stabilization of SAs often results in bond polarization, which can lead to extensive charge transfer from or to the metal, originating cationic or anionic species. A survey of the predicted electronic state of $\mathrm{Au}, \mathrm{Pt}$, and $\mathrm{Pd}$ atoms on distinct hosts, ${ }^{[44-62]}$ quantified based on the robust method for charge analysis introduced by Bader, ${ }^{[63]}$ emphasizes the significant potential changes in the degree of electron transfer (Fig. 3). As expected, a much narrower range of charge states is anticipated for SAAs than for SACs based on oxide- or carbon-based materials. In the latter hosts, noteworthy differences are also observed for inequivalent sites on the same materials. For example, the calculated values for gold atoms bonded to axial or pyridine sites in $\mathrm{N}$-doped single wall carbon nanotubes were 0.9 and $0.41 \mathrm{e}^{-}$, respectively. ${ }^{[62]}$

Another consideration is that SACs by definition do not contain adjacent metal centers. Thus, ensemble effects can be foreseen in reactions requiring close proximity between active sites. Indeed, the activity of isolated metal ions has been confirmed in several applications in gas-phase catalysis, ${ }^{[64]}$ but they are not always effective. Similarly, SACs may be inactive in certain applications unless the reaction proceeds via a distinct mechanism and/or the matrix can fulfill the required catalytic role. For example, pyridinic $\mathrm{N}$ sites in carbon nitride have been shown to adsorb hydrogen atoms in the selective hydrogenation of alkynes leaving the metal center free to coordinate the organic substrate. ${ }^{[65]}$ The integration of polydentate coordination sites may enable highly flexible bonding of the metal to the host. In this respect, carbon-based hosts appear to offer huge potential as the precision synthesis becomes more advanced.

Understanding the complex interplay between the structural and electronic effects described in this section and the catalytic performance will be essential to develop design principles for SACs. Surprisingly, most studies to date have examined different types of host independently. As recently stressed in a first theoretical attempt to provide a common framework for evaluation, efforts to compare the properties of SACs based on different materials will undoubtedly be of great value. ${ }^{[50]}$ Improving knowledge of how SACs evolve under reaction conditions and how this affects the properties is also crucial to develop representative correlations with the performance. The

Sharon Mitchell is a scientist in the
group of Advanced Catalysis
Engineering at ETH Zurich. Her
research focuses on the design of
novel heterogeneous catalysts,
including those based on single
atoms, which is approached through
the advanced characterization of
structure-property relations over
relevant time and length scales.
Evgeniya Vorobyeva is a PhD
student in the group of Prof. Pérez-
Ramirez. Her research centers on
the development of carbon nitride
as a platform for single-atom
heterogeneous catalysts. This
embraces the controlled synthesis,
advanced characterization, and
testing in relevant applications.
Javier Pérez-Ramirez holds the
Chair of Catalysis Engineering at
ETH Zurich. His research pursues
the design of heterogeneous
catalysts and reactor concepts
devoted to sustainable
technologies. His contributions
have been recognized by various
awards including the Sustainable
Energy Award (2017), which was in
part for his work on single-atom
catalysis.



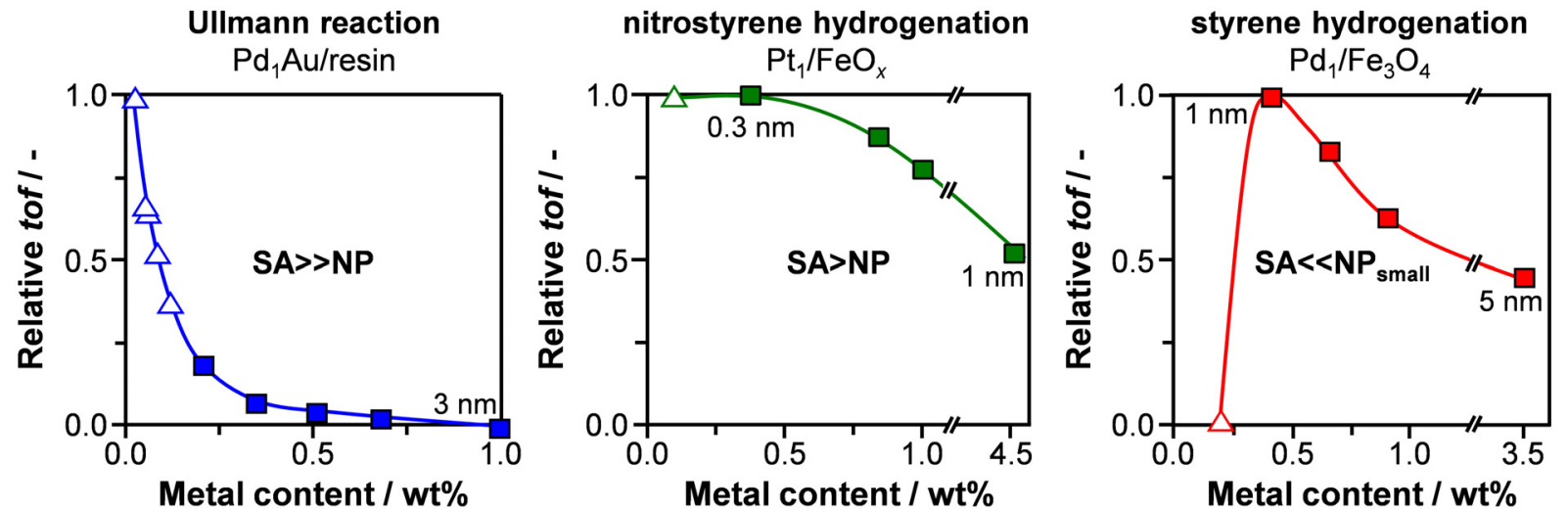

Figure 4. Trends in relative tof (based on the total metal content and normalized to the maximum value) upon reducing the atomic population of metal NPs (solid squares) to SAs (open triangles). The range of average nanoparticle diameter is indicated. Adapted with permission of references [69], [71], and [73], respectively.

major potential influence of dynamic effects such as the generation $^{[66]}$ or aggregation ${ }^{[67]}$ of single-atom active centers during catalysis, as well changes in their coordination during the catalytic cycle ${ }^{[68]}$ is increasingly recognized.

\section{Reactivity of SACs}

SACs are now known to be active in multiple thermo, electro, and photocatalytic applications. However, the vast majority of studies have focused on reactions that are traditionally heterogeneously-catalyzed, with the goal of enhancing the atom efficiency. Comparatively, few studies have faced SACs with homogeneous systems in fine-chemical syntheses. In this section, we examine how and why the reactivity of SACs differs from metal nanoparticles and soluble metal complexes, when this enhances or depresses the performance, and what options have been studied to control these effects.

\subsection{SACs versus Nanoparticles}

Verification of the improved metal utilization upon reducing the atomic population from thousands in a typical nanoparticle to one in an SAC is nontrivial. Most commonly this is approached by comparing the turnover frequency (tof) per mole of metal in the catalyst. Although this has well-known limitations for evaluating relative activity because only a fraction of the metal atoms in NPs and even in SACs may be contributing to this, the quantification of the actual number of active atoms is beyond current experimental capabilities. Variation of the metal speciation is widely approached by reducing the amount of metal in the catalyst and may be reported in terms of the loading, size of the species deposited, or surface coverage. Analysis of the reported trends reveals that they be well-described by three characteristic scenarios (Fig. 4). If SAs exhibit a much higher activity than NPs (SAs>>NPs) such that the contribution of the latter becomes insignificant a sharp increase in catalytic turnover will be observed at low metal content, when the majority of metal centers become spatially isolated. ${ }^{[69,70]}$ On the other hand, if NPs can also catalyze the reaction (SAs>NPs) then the activity will rise more gradually with increasing dispersion until it reaches a plateau as the metal species tend toward single atoms. ${ }^{[71,72]}$ In contrast, if SAs are ineffective (SA $<<N P s)$ then the activity may initially increase as the metal content is reduced due to higher dispersion, before falling sharply to close to zero when metal clusters are no longer present in the sample. ${ }^{[73]} \mathrm{A}$ fourth scenario can be envisaged in which the activity of SAs is non negligible, but small NPs are optimal in which case the activity would not drop to zero at low contents, but no such result was identified in our literature analysis.

A lack of activity may not always signify that the efficiency cannot be improved over SACs. For a given metal, drastic distinctions in the performance can be observed depending on the host. However, there is also no fundamental reason why SAs should also be most active. In this regard, controlled experimental studies have established the superior performance of metal clusters supported on a given support for different applications, for example $\mathrm{Pd}_{1} / \mathrm{TiO}_{2}$ was found to be inactive for $\mathrm{CO}$ oxidation, while size-selected clusters demonstrated a nonlinear activity dependence (Fig. 5). ${ }^{[7]}$ Calculations have similarly predicted lower barriers over multiatom ensembles in some reactions. ${ }^{[75,76]}$ On the other hand, SACs may offer other benefits such as higher resistance to coking or improved stability to sintering. To further explore the potential, here we examine the performance in selected applications with respect to their predecessors.

Water-gas shift (WGS). The WGS reaction has been widely studied over SACs. Highly dispersed nonmetallic $\mathrm{Au}$ or $\mathrm{Pt}$ species were anticipated to catalyze this reaction long before the presence of isolated centers was directly evidenced since the removal of metallic NPs by leaching did not impact the activity. ${ }^{[77]}$ Detailed studies by Flytzani-Stephanopoulos et al. have demonstrated synthetic approaches to obtain $\mathrm{Au}-\mathrm{O}(\mathrm{OH})_{x^{[78]}}$ or Pt-O $(\mathrm{OH})_{x}{ }^{[35]}$ as the primary active species on both reducible and irreducible hosts, which was supported by the comparatively low activity over analogous NP-based catalysts. For both metals, Arrhenius plots of tof evidenced unified trends (exemplified for 

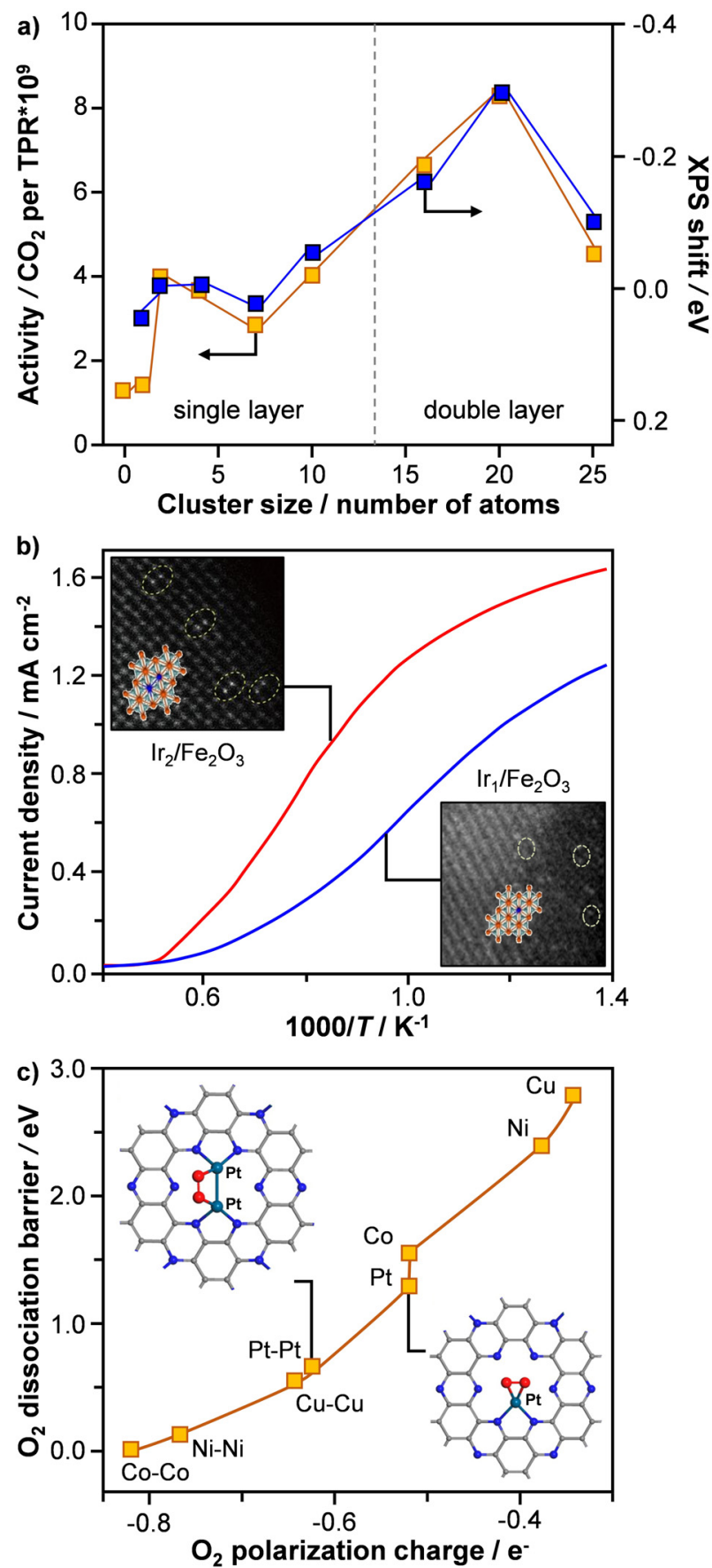

Figure 5. a) $\mathrm{CO}$ oxidation activity of $\mathrm{Pd}_{n} / \mathrm{TiO}_{2}$ catalysts and correlation with the shift in the $\mathrm{Pd} 3 \mathrm{~d}$ band determined by XPS. b) Performance of $\operatorname{Ir}_{1} / \mathrm{Fe}_{2} \mathrm{O}_{3}$ and $\mathrm{Ir}_{2} / \mathrm{Fe}_{2} \mathrm{O}_{3}$ in the photooxidation of water and c) predicted $\mathrm{O}_{2}$ dissociation barriers over various metal atoms and dimers supported on $\mathrm{C}_{2} \mathrm{~N}$. Adapted with permission of references [74], [75], and [76], respectively.

Au-SACs in Fig. 6a), the equivalent estimated activation energy supporting the similar active-site structure. The apparent secondary role of the host was linked to the ability to form regenerable $\mathrm{OH}$ groups proximal to $\mathrm{CO}$ molecules adsorbed on the $\mathrm{M}-\mathrm{O}_{x}$ species. For reducible oxides this occurs readily through the catalytic dissociation of $\mathrm{H}_{2} \mathrm{O}$, but for inert supports promotors such as hydrophilic alkali metals are typically required to supply $-\mathrm{OH}$. Consistently, linear trends were observed between the reaction rate and the concentration of surface hydroxyls in promoted and unmodified SACs based on irreducible supports (Fig. 6b). ${ }^{[6]}$ Density functional theory (DFT) calculations performed to gain insight into the role of sodium ions identified an Au/Na ratio of 9 to be most stable, which was close to the optimum value observed experimentally. The introduction of electron withdrawing $(\mathrm{O} / \mathrm{OH})$ groups led to an increase in the Bader charge (illustrated for the four structure identified to be most probably in Fig. 6c) confirming the creation of cationic gold species with charges close to those expected for bulk $\mathrm{Au}_{2} \mathrm{O}$ or $\mathrm{Au}_{2} \mathrm{O}_{3}$.

A lack of appropriate tailoring of the surface composition could explain why other groups have reported contradictory trends. For example, significantly reduced (by up to $90 \%$ ) metal specific activity was observed upon the selective leaching of NPs from an Au/Mo-C catalyst leaving predominantly SAs. ${ }^{[79]}$ Monitoring the evolution of $\mathrm{Pt}_{n} \mathrm{Com}_{m} / \mathrm{Co}_{3} \mathrm{O}_{4}$ catalysts by in situ X-ray absorption spectroscopy, Zhang et al. also reported that while singly dispersed $\mathrm{Pt}_{1} \mathrm{Co}_{n}$ nanoclusters catalyzed the reaction at temperatures $<473 \mathrm{~K}$, at higher temperatures $\mathrm{Pt}_{m} \mathrm{Co}_{m}$ $(m>1)$ nanoclusters formed that when re-evaluated in the low-temperature regime were up to 3 times more active than the initial SAC. ${ }^{[80]}$ In an extreme case, Stair et al. reported that only NPs were active in a study of Pt catalysts based on various supports. ${ }^{[81]}$ IR evidence showed that bands related to $\mathrm{CO}$ adsorption on SAs remained unchanged during the low-temperature WGS reaction, while those associated with NPs quickly reacted with water.

A combined DFT and microkinetic assessment shed some light on the apparently disparate experimental observations. ${ }^{\left[{ }^{[2]}\right.}$ Comparing the behavior of $\mathrm{Pt}$ on a reducible $\mathrm{TiO}_{2}(110)$ surface, the authors found that both isolated $\mathrm{Pt}^{2+}$ sites and $\mathrm{Pt}$ interface edge sites on NPs exhibit low-temperature WGS activity, while corner interface sites become most active at higher temperatures. Thus, depending on the reaction conditions, SAs may display similar activities to clusters $(T<573 \mathrm{~K})$, or NPs may be most active ( $T>573 \mathrm{~K}$ ). A redox pathway involving the oxygen of the support was reported to operate in both cases. Two $\mathrm{CO}$ molecules were claimed to adsorb on the $\mathrm{Pt}$ atom, one weakly that readily reacts and one more strongly, acting as a ligand that remains attached to the $\mathrm{Pt}$ atom throughout the catalytic cycle, accounting for the reported nondisappearance of the CO IR band. Nevertheless, a subsequent experimental comparison of $\mathrm{Pt}_{1} / \mathrm{FeO}_{x}$ and $\mathrm{Pt} / \mathrm{FeO}_{x}$ catalysts by Chen et al. further supported increased specific rates with decreasing atomic population. ${ }^{\left[{ }^{[3]}\right.}$ Through in-depth characterization the authors suggest an associative mechanism, in which $\mathrm{CO}$ reacts with $\mathrm{OH}$ species generated by the activation of $\mathrm{H}_{2} \mathrm{O}$ on the support to form intermediate formates, plays a crucial role over NPs, while a redox mechanism occurs over the SAC.

Moderately enhanced tof compared to supported NPs has 

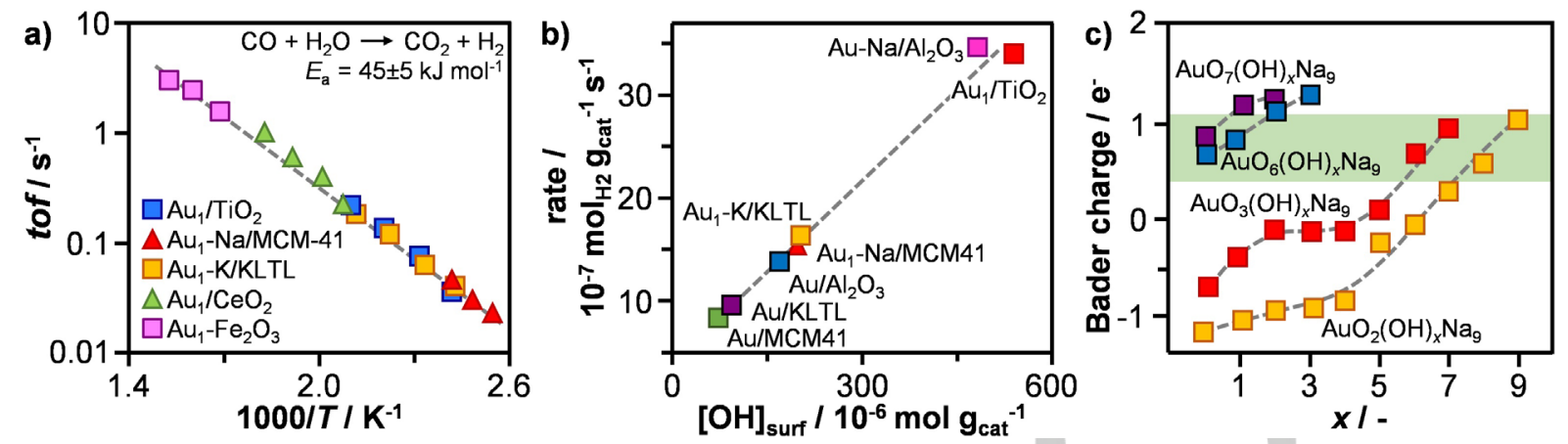

Figure 6. Performance of Au-SACs based on various hosts in the WGS reaction. a) Reaction scheme and Arrhenius plot of the tof. Correlation between b) the reaction rate and surface concentration of hydroxyls and c) the calculated Bader charge and the amount of hydroxyls in an $\mathrm{AuO}_{6}(\mathrm{OH})_{x} \mathrm{Na}_{9} \mathrm{cluster}$. In $\left.\mathbf{c}\right)$, the shaded area corresponds to values between bulk $\mathrm{Au}_{2} \mathrm{O}$ and $\mathrm{Au}_{2} \mathrm{O}_{3}$. Adapted with permission of reference [36].

also been evidenced over SACs of other metals including $\mathrm{Ir}_{1} / \mathrm{FeO}_{\mathrm{x}}(2.6 \text { times})^{[84]}$ and $\mathrm{Rh}_{1} / \mathrm{TiO}_{2}$ (4 times). ${ }^{[85]}$ The continued debate over the most effective species likely reflects the need for improved control in the synthesis of supported subnanometer metal structures. Unfortunately, most comparisons have been made over catalysts with significantly different metal contents, which could also impact the specific interaction with the host and hence the generality of the conclusions derived. Although strategies to promote the metal specific activity are known, practically the choice of host is expected to be critical since it will influence the maximum loading capacity of an SAC. To date, limited understanding of the distribution and stability of atomically-dispersed species. In the case of inert supports, little is known about the scope of the stabilization with alkali/alkaline earth metal additives. Synergies between the host and the active metal, as predicted for $\mathrm{Pt}_{1} / \mathrm{Mo}_{2} \mathrm{C}$, could also be exploited. ${ }^{[86]}$

$\mathrm{CO}$ oxidation. $\mathrm{CO}$ oxidation is a prototypical reaction for both applied and fundamental studies over SACs. As for the WGS reaction, high activity is often reported, but the impact of the SAC design appears more influential. Due to the known activity in this reaction, Au-based systems have attracted significant attention. However, most experimental evidence points towards the lower activity of SAs than metal clusters. ${ }^{[87-90]}$ On the other hand, Qiao et al. highlighted a potential advantage of SAs, demonstrating the increased resistance to sintering of $\mathrm{Au}_{1} / \mathrm{FeO}_{\mathrm{x}}$ compared to larger $\mathrm{Au}$ nanostructures. ${ }^{[51]} \mathrm{Au}_{1} / \mathrm{CeO}_{2}$ was later shown to be stable for the preferential oxidation of $\mathrm{CO}$ in $\mathrm{H}_{2}$-rich streams. ${ }^{[91]}$

The challenge of developing an active SAC has inspired various ab initio studies, which aim to elucidate the optimal charge state and geometry of Au species. ${ }^{[58,62,92]}$ Maximizing the degree of oxidation by doping with a second transition metal was predicted to yield the highest activity for $\mathrm{Au}_{1} / \mathrm{TiO}_{2}$ systems ${ }^{[58]}$ In contrast, a study of $\mathrm{B}$ - and $\mathrm{N}$-doped carbons indicated that anionic $\mathrm{Au}$ species formed in the presence of boron were more active since otherwise $\mathrm{CO}$ was too strongly adsorbed on $\mathrm{Au}$ cations. ${ }^{[62]}$ This resembles the mechanistic path proposed for $\mathrm{Au} / \mathrm{CeO}_{2}$, in which the oxidation state of $\mathrm{Au}$ is initially negative and becomes positively charged upon $\mathrm{O}_{2}$ dissociation and thus $\mathrm{CO}$ can adsorb and readily reacts with a surface oxygen to form
$\mathrm{CO}_{2} \cdot{ }^{\left[{ }^{[3]}\right.}$ The main kinetic pathway and catalytically active sites on $\mathrm{Au} / \mathrm{TiO}_{2}$ are anticipated to be highly dependent on the temperature and oxygen partial pressure, the activity dominated by a transient $\mathrm{Au}-\mathrm{CO}$ species under oxidizing conditions and $T<400 \mathrm{~K} \cdot{ }^{[94]}$ The dynamic formation of SAs from small nanostructures under reaction conditions was also proposed to account for the distinctive size effect evidenced over $\mathrm{Au} / \mathrm{CeO}_{2}{ }^{[91]}$

In the case of $\mathrm{Pt}$, the superiority of $\mathrm{SAs}$ is also unclear. A stable $\mathrm{Pt}_{1} / \mathrm{FeO}_{x}$ was shown to display around double the tof of a NP-based analogue. ${ }^{[11]}$ However, the Pt content was limited $(0.17 \mathrm{wt} \%)$ and although a high initial dispersion $\left(d_{\text {particle }}<2 \mathrm{~nm}\right)$ was confirmed in the reference catalyst, its stability was not demonstrated. Early studies on $\theta-\mathrm{Al}_{2} \mathrm{O}_{3}$ observed activity over SAs, but the light-off temperature decreased with increasing metal content (from $0.18-2 \mathrm{wt} \%$ ) indicating clusters or NPs to be the more active species. ${ }^{[12]}$ Polyhedral ceria nanorods were shown to effectively stabilize SAs with higher metal contents than $\theta-\mathrm{Al}_{2} \mathrm{O}_{3},{ }^{[95]}$ but the low-temperature activity was also limited, which was attributed to inactive lattice oxygen and the strong binding of $\mathrm{CO}$ molecules to $\mathrm{Pt}$ ions. The performance could be drastically improved by steam treatment at $1023 \mathrm{~K}$, reducing the temperature required to reach $100 \%$ conversion by $>150 \mathrm{~K} \cdot{ }^{[14]}$ This was attributed to the activation of surface oxygen generating hydroxyls, which differed from those formed upon cofeeding water during the reaction. While the latter can also significantly increase the activity of $\mathrm{Pt}_{1} / \mathrm{CeO}_{2}$, the effect disappears as soon as $\mathrm{H}_{2} \mathrm{O}$ is removed from the feed. ${ }^{[96]}$ The possibility of accessibility constraints due to diffusion of the $\mathrm{Pt}$ species into the $\mathrm{CeO}_{2}$ lattice was excluded by the similar activity to $\mathrm{Pt}_{1} / \mathrm{Al}_{2} \mathrm{O}_{3}$. Nonetheless, embedding in the support has been identified as the main mechanism of activity losses in other systems ${ }^{[97]}$ Unlike the WGS reaction, widely different intrinsic tof have been evidenced over Pt atoms on different supports, indicating that the interaction controls the catalytic behavior of SACs in CO oxidation. ${ }^{[98]}$

Differently from $\mathrm{Au}$ and $\mathrm{Pt}$, atomic dispersion appears crucial for low-temperature $\mathrm{CO}$ oxidation over $\mathrm{Pd} .{ }^{[99]} \mathrm{Pd}$ atoms on $\mathrm{La}_{2} \mathrm{O}_{3}$-modified $\mathrm{Al}_{2} \mathrm{O}_{3}$ were found to show exceptional activity where metallic $\mathrm{Pd}$ surface sites are inactive due to poisoning by strongly adsorbed $\mathrm{CO}^{.[47]}$ In operando X-ray absorption 

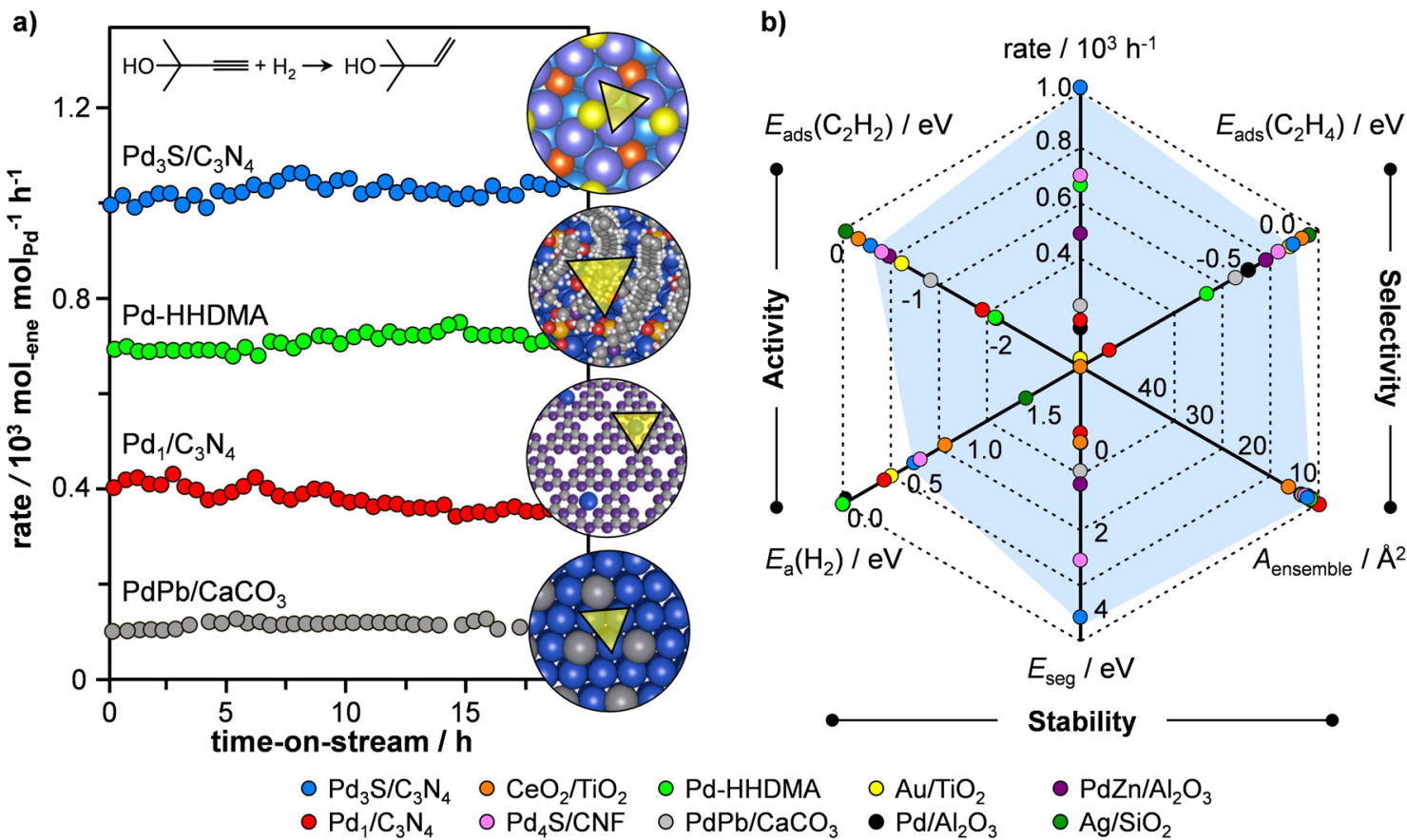

Figure 7. Performance of a Pd-SAC with respect to established catalysts for alkyne semi-hydrogenation. a) Reaction scheme and rate of alkene formation with time in the continuous semi-hydrogenation of 2-methyl-3-butyn-2-ol. b) Radar plot of theoretical indicators for the activity: the alkyne adsorption energy $\left(E_{\text {ads }}\left(\mathrm{C}_{2} \mathrm{H}_{2}\right)\right)$ and the activation energy for $\mathrm{H}_{2}$ dissociation $\left(E_{\mathrm{a}}\left(\mathrm{H}_{2}\right)\right)$, selectivity: the alkene adsorption energy $\left(E_{\text {ads }}\left(\mathrm{C}_{2} \mathrm{H}_{4}\right)\right)$, and the ensemble area $\left(A_{\text {ensemble }}\right)$, and the stability: the segregation energy $\left(E_{\text {seg }}\right)$.

spectroscopy evidenced cationic Pd intermingled with La as the active site. Although deactivation due to sintering became more significant with increasing metal loading, the activity losses could be reversed by redispersing the $\mathrm{Pd}$ via high-temperature treatment in air. $\mathrm{Pd} / \mathrm{CeO}_{2}$ stands out as a stable alternative. ${ }^{[100,101]}$ Still, the nature of the active site between Pd ions doped in the surface of the host or $\mathrm{PdO}_{x}$ species has been actively debated. This partly arose from the lack of a suitable surface model to describe $\mathrm{CO}$ adsorption of doped Pd atoms, ${ }^{[102]}$ but a square-planar configuration was also recently put forward that overcame this issue. ${ }^{[103]}$

In efforts to predict more efficient catalysts, various groups have computed the performance of SACs based on different hosts. ${ }^{[6,104-107]}$ For instance, five SACs $\left(\mathrm{Rh}_{1}, \mathrm{Pd}_{1}, \mathrm{Ru}_{1}, \mathrm{Ti}_{1}\right.$, and $\mathrm{Co}_{1}$ supported on $\mathrm{FeO}_{x}$ ) were anticipated to be more active than $\mathrm{Pt}_{1} / \mathrm{FeO}_{x}{ }^{[104]} \mathrm{An}$ independent study later also found that $\mathrm{Pd}_{1} / \mathrm{FeO}_{x}$ should be more active. ${ }^{[46]} \mathrm{Cu}_{1} / \mathrm{C}$-doped hexagonal boron nitride, ${ }^{[105]} \mathrm{Ag}_{1} / \mathrm{MgO},{ }^{[106]}$ and $\mathrm{Pd}_{1} / \mathrm{Mo}_{2} \mathrm{CO}_{2}{ }^{[107]}$ have also been reported as potentially active. $\mathrm{Ir}_{1} / \mathrm{FeO}_{x}$ was predicted to be less active than $\mathrm{Pt}_{1} / \mathrm{FeO}_{x}$ and this was confirmed experimentally. ${ }^{[108]}$ The performance of many of the systems identified has yet to be confirmed experimentally, and in some cases the synthesis has still not been reported.

Hydrogenations and related reactions. Selective hydrogenations are key catalytic transformations with industrial applications ranging from the multi-ton purification of refinery products to the kilo scale preparation of fine chemicals. SACs have demonstrated activity in the hydrogenation of different functional groups, ${ }^{[26,65,71,109,110]}$ and the performance compared to
NPs depends on the application. In the semi-hydrogenation of alkynes, a recent comparison of state-of-the-art Pd catalysts highlighted that although very selective $\mathrm{Pd}$ atoms supported on carbon nitride are not very active and thus the overall rate of product formation per mole of metal was similar to that of a catalyst containing much larger NPs (Fig. 7a). ${ }^{[111]}$ Comparatively, other selective systems such as ligand-modified Pd NPs or supported $\mathrm{Pd}_{x} \mathrm{~S}$ systems displayed significantly increased efficiency. Analysis of key theoretical parameters suggests that this could be linked with the relatively strong adsorption strength of the alkene on the $\mathrm{Pd}$ atoms (Fig. 7b). Although the $\mathrm{H}_{2}$ dissociation energy was slightly higher than the bare metal, this was not thought to be the main cause of the limited activity since other efficient catalysts exhibited higher values.

In related work, ${ }^{[42,112]}$ a strong inverse correlation was demonstrated between the degree of oxidation of $\mathrm{Pd}$ species and the performance (Fig. 8a). As expected due to the differing mechanisms, distinct behavior was observed for Pd NPs supported on the same host. A similar trend with the metal oxidation state was seen for Au-SACs in acetylene hydrochlorination, a reaction with a closely related mechanism of hydrogen addition (Fig. 8b). ${ }^{[112]}$ The findings suggests that by tuning the strength of the metal-host interaction to preserve the metallic nature it may be possible to develop more efficient SACs that achieve the goal of improved metal utilization. In other applications, cationic metal centers appear favorable. For example, in the chemoselective hydrogenation of nitroarenes increasing the dispersion to SAs correlated to both increased tof and higher oxidation state, judged by the increased white-line 

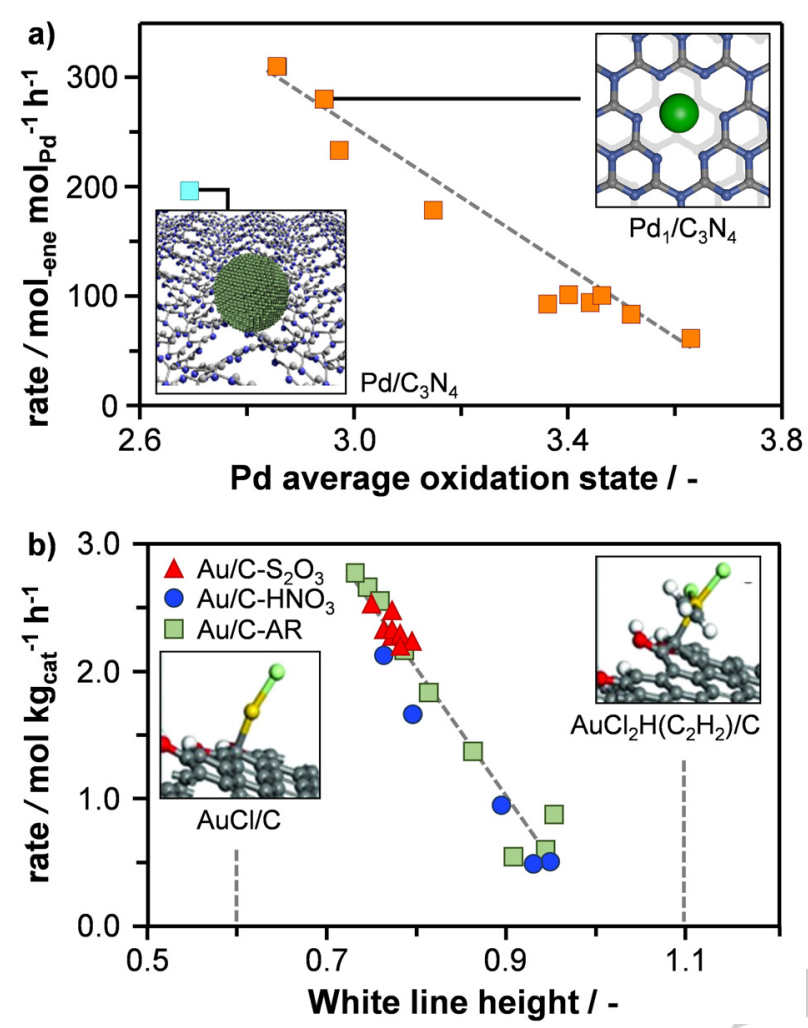

Figure 8. Correlation between the metal oxidation state and the activity in a) the hydrogenation of 2-methyl-3-butyn-2-ol and b) the hydrochlorination of acetylene. Adapted with permission of ref. [113] (b)

intensity derived from EXAFS data. ${ }^{[71]}$ However, similar performance was identified over ensembles consisting of several to tens of atoms and thus the benefits of active site isolation atoms remain unclear. The choice of the support was identified to have a dramatic effect. In particular, systems based on $\mathrm{SiO}_{2}$ and $\mathrm{Al}_{2} \mathrm{O}_{3}$ were unable to achieve a similar selectivity to $\mathrm{Pt}_{1} / \mathrm{FeO}_{\mathrm{x}}$, which was attributed to the preferential adsorption of the nitro group on basic or reducible oxides.

Electrocatalysis. The electrochemical application of SACs has also generated significant attention. ${ }^{[5]}$ These have mainly focused on Pt-based catalysts, ${ }^{[55,114-117]}$ due to their established practical relevance, or alternatives based on earth-abundant metals (primarily $\mathrm{Co}$ or $\mathrm{Fe}$ ). ${ }^{[118-120]}$ Two additional considerations in electro- compared to thermal catalysis are the host conductivity and the $\mathrm{pH}$ of the reaction media. In the majority of cases, the performance of SACs has been evaluated with respect to the commercial Pt/C NP-based catalyst. The observations depend strongly on the application. Significantly enhanced activity has been reported in the hydrogen evolution reaction (HER) over pseudo-SACs based on $\mathrm{N}$-doped graphene nanosheets (37 times) ${ }^{[55]}$ or single-walled carbon nanotubes (up to 333 times ${ }^{[114]}$ in acidic media. Moderately enhanced mass activity (4 times) and improved stability were also demonstrated in neutral media over an SAC based on CoP nanotubes supported on a Ni foam. ${ }^{[15]}$ However, in all cases it was not possible to exclude the potential role of clusters based on the reported data. The comparative study of $\mathrm{Pt}$ SAs and multiatom ensembles on a bismuth electrode, later found that the HER rate in acidic media increased with the number of atoms (up to 9). ${ }^{[16]}$ While strong correlations were evidenced, no complementary characterization data was provided to confirm the speciation or stability. In the case of other metals, despite promising observations, the comparative performance of NPs has not been explored.

Improved Pt utilization is a key target for the cathode of the oxygen reduction reaction (ORR), which is required at the proton exchange membrane fuel cells. SACs based on $\mathrm{N}$ or $\mathrm{S}$ containing carbons are among the most active to date. ${ }^{[28,54,121]}$ However, surpassing the efficiency of $\mathrm{Pt} / \mathrm{C}$ is challenging since the reaction has been found to proceed by a $2 \mathrm{e}^{-}$pathway, producing less electricity than the alternative $4 \mathrm{e}^{-}$pathway. On the other hand, this presents an efficient route for the $\mathrm{H}_{2} \mathrm{O}_{2}$ synthesis, in which case higher selectivity is expected upon complete elimination of NPs and clusters. The improved performance of a $\mathrm{Pt}_{1} / \mathrm{TiC}$ catalyst than $\mathrm{Pt}_{1} / \mathrm{TiN}$ indicated that the support can strongly influence the performance. ${ }^{[34]}$ Apart from $\mathrm{Pt}$, $\mathrm{Co}$, and $\mathrm{Fe}$ are the most widely studied metals, the study of which has been stimulated by highly promising experimental and theoretical evidence..$^{[122-127]}$

Interesting prospects to tune the mechanism have been reported in the oxidations of methanol (MOR), ethanol (EOR), and formic acid (FAOR). The lack of activity of SACs in MOR has been considered as a diagnostic test to confirm the isolation of metal centers ${ }^{[127]} \mathrm{A}$ significant nuclearity effect was evidenced through the controlled deposition of Pt clusters of different size. While some activity has been reported, SACs do not appear to be the most active for EOR. ${ }^{[5]}$ Opposite behavior was reported in FAOR, with SACs promoting a direct pathway that avoids surface poisoning by $\mathrm{CO}$ leading to high mass activity. ${ }^{[128]}$

\subsection{SACs versus Metal Complexes}

Studies applying SACs in challenging processes that remain reliant on homogeneous catalysts, like C-C bond forming, ${ }^{[68,69,129-}$ 132] selective hydrocarbon oxidations, ${ }^{[133-144]}$ and hydroformylation ${ }^{[145-147]}$ point toward highly interesting potential to implement efficient recoverable alternatives. To exemplify this we will focus on Suzuki coupling, which has become an essential tool for the development of agrochemical, pharmaceutical, and other fine chemical products. Despite its success, Suzuki coupling still poses many challenges, not least related to steep catalyst costs. Recently, Pd atoms immobilized on graphitic carbon nitride were shown to surpass state-of-theart homogeneous and heterogeneous systems in this reaction (Fig. 9a) with a broad substrate scope, becoming one of the first SACs to clearly demonstrate tangible prospects for the heterogenization of an important industrial process. ${ }^{[68]}$ In particular, $\mathrm{Pd}_{1} / \mathrm{C}_{3} \mathrm{~N}_{4}$ demonstrated a remarkable 16-fold increased tof and similar or increased purified yields of the desired coupling product compared to tetrakis(triphenylphosphine)palladium, the best homogeneous 
a)

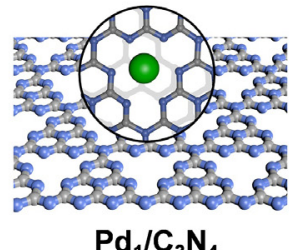

tof, $Y$

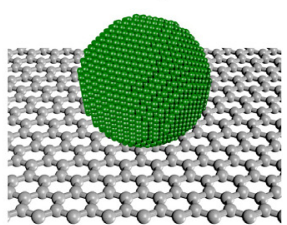

$\mathrm{Pd} / \mathrm{C}$

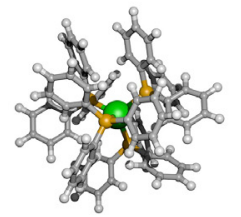

$\mathrm{Pd}\left(\mathrm{PPh}_{3}\right)_{4}$

$34 \mathrm{~h}^{-1}, 41 \%$

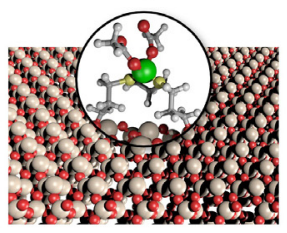

$\mathrm{PdAC}-\mathrm{MPES} / \mathrm{SiO}_{2}$

$57 \mathrm{~h}^{-1}, 13 \%$ b)
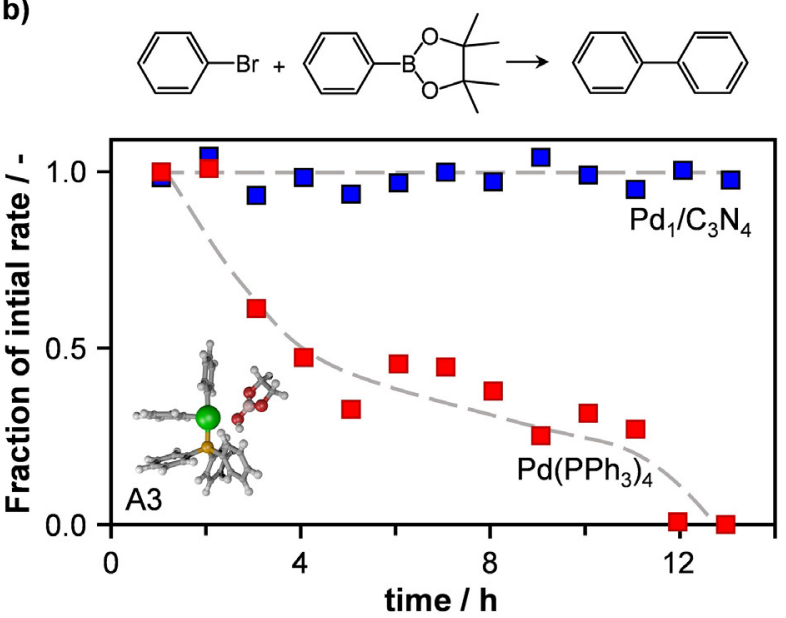

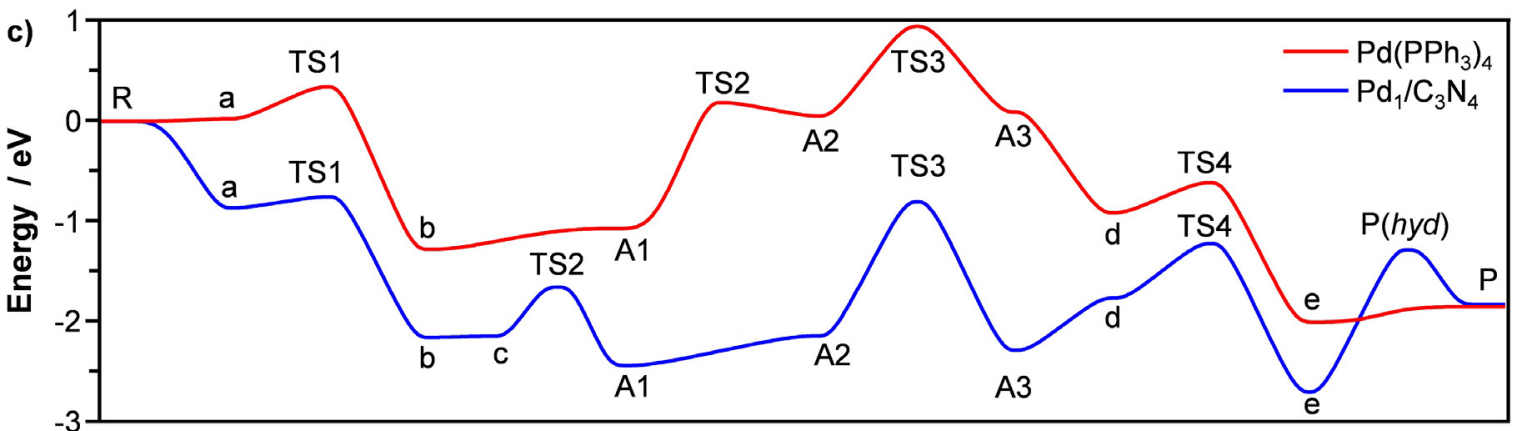

Reaction coordinate / -

d)

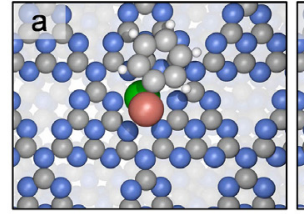

NCN, $q \quad 6.00,0.52$

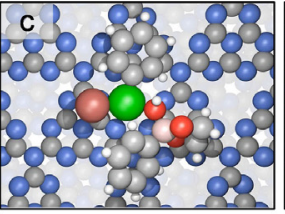

$2.76,0.75$

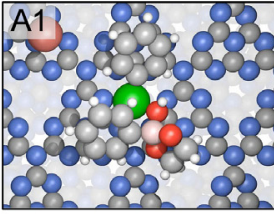

$3.31,0.68$

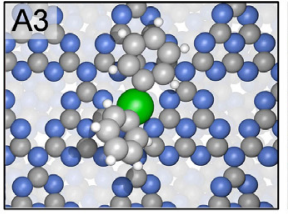

$2.63,0.45$

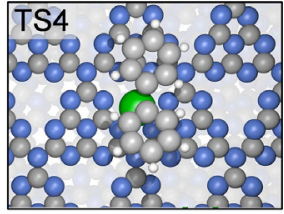

$3.04,0.4$

Figure 9. Performance of a Pd-SAC with respect to state-of-the-art catalysts in the continuous Suzuki coupling of bromobenzene and phenylboronic acid pinacol ester. a) Schemes of the catalysts and respective tof and yield. b) Reaction scheme and variation in the activity with time. c) DFT-calculated reaction profiles of the SAC and homogeneous $\mathrm{Pd}\left(\mathrm{PPh}_{3}\right)_{4}$ catalysts and d) the optimized structures of the SAC illustrating how the coordination of the Pd atom (green) within the carbon nitride cavity adapts to the charge along the reaction profile, quantified by the normalized coordination number (NCN) and Bader charge ( $q$ ), respectively. The inset in (b) shows the structure of the homogeneous catalyst at the point at which it has lost three of its original ligands.

C-C coupling catalyst identified under the continuous flow conditions studied. Comparatively, supported nanoparticles were found to be inactive, while a grafted form of palladium acetate attained limited yields and experienced substantial metal leaching after reuse in multiple tests, which was not observed for the SAC. In contrast to the homogeneous catalyst, for which rapid activity losses were observed after just $2 \mathrm{~h}, \mathrm{Pd}_{1} / \mathrm{C}_{3} \mathrm{~N}_{4}$ displayed constant performance for $12 \mathrm{~h}$ on stream (Fig. $9 \mathrm{~b}$ ).

The superior catalytic properties of $\mathrm{Pd}_{1} / \mathrm{C}_{3} \mathrm{~N}_{4}$ could be fully explained at the molecular level by the specific structure of the catalyst (Fig. 9c). The metal binding site features six nitrogen groups that enable an almost continuously variable coordination pattern that adapts to the charge on $\mathrm{Pd}$ along the reaction coordinate, which minimizes the energy requirement for each reaction step and gives rise to the high stability. In contrast, the lability of ligands in the homogeneous systems is essential, but also increases the propensity of metal aggregation, consistent with the rapid catalyst degradation observed for $\mathrm{Pd}\left(\mathrm{PPh}_{3}\right)_{4}$. Alternatively, if the ligand-metal interaction is too strong then the organometallic catalyst is poorly active as activation requires ligand removal. Considering that the homogeneous catalyst would require periodic replacement and that the $\mathrm{Pd}_{1} / \mathrm{C}_{3} \mathrm{~N}_{4}$ can be economically produced, the application of this catalyst can be envisaged to have a major cost benefit.

The question of whether supported metal clusters are superior candidates to SACs remains important in this arena. 
For example, $\mathrm{Ru}_{3}$ clusters stabilized in a MOF-derived $\mathrm{N}$-doped carbon were reported to be more efficient than $\mathrm{Ru}_{1}$ species for the oxidation of 2-amino-benzaldehyde. ${ }^{[137]}$ This was linked to distinct adsorption configurations, where the trimeric site could bond to both the hydroxyl and amino groups of the substrate, thereby facilitating the reaction. Au-SACs based on functionalized carbon nanotubes were also shown to be inactive in the oxidation of thiophenol, but gold clusters formed during the reaction exhibited comparable activity to that of sulfhydryl oxidase enzymes. ${ }^{[136]}$ On the other hand, a comparative study of $\mathrm{Pd}_{n} / \mathrm{CeO}_{2}$ ( $n=1$ or 6 ) catalysts evidenced the remarkably enhanced activity of SAs in the oxidation of benzyl alcohols, which was attributed to the more intimate interaction with the host compared to the clusters. ${ }^{[144]}$ Moving away from precious metals, exciting selective oxidation activity has also been reported for transition metals supported on $\mathrm{N}$-doped

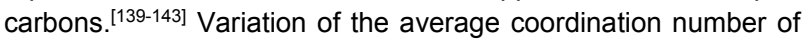
$\mathrm{FeN}_{x}(x=4-6)$ species in N-doped graphene was shown to yield up to an order of magnitude difference in tof for the selective oxidation of hydrocarbons. ${ }^{[142]}$

\section{Conclusions and Outlook}

Based on the analysis presented in this review, several important points for reflection emerge. Crucially, it has highlighted that the superior metal specific activity of SACs is still under debate in most applications. This could be due to a number of reasons. Firstly, SACs have predominantly been studied in reactions that are already run over heterogeneous catalysts. However, compared to supported NPs, SACs lack metal ensembles and usually nonmetallic in nature, and thus it is not directly obvious that they will display enhanced catalytic performance with respect to the former. This calls for analysis that is more critical and the application-oriented design of SACs. In this regard, there is growing awareness of the fundamental influence of the choice of host. Preliminary efforts to modify the type and strength of metal-host interaction have highlighted attractive possibilities to change performance rankings, opening new prospects through smart engineering of the architecture, for example to harness the potential of earth-abundant metals. A grand challenge lies in improving the molecular-level understanding of the active-site structure, including how this evolves under reaction conditions, and the associated reaction paths. To date, knowledge on this aspect primarily has been derived from theoretical analyses. Perhaps unsurprisingly given the different structural features, these have shown that SACs display almost universally distinct catalytic cycles with respect to traditional catalysts. Powerful approaches combining advanced surface science techniques with relevant model samples and in operando studies, ${ }^{[147]}$ together with improvements in spatial resolution will be invaluable both to bring revolutionary insights and to corroborate the first principles predictions. Further targeted efforts to stabilize multiatom clusters will also be beneficial to help confirm the effects of nuclearity on reactivity patterns of atomically-dispersed metals.

Despite the often closer similarity in electronic structure and

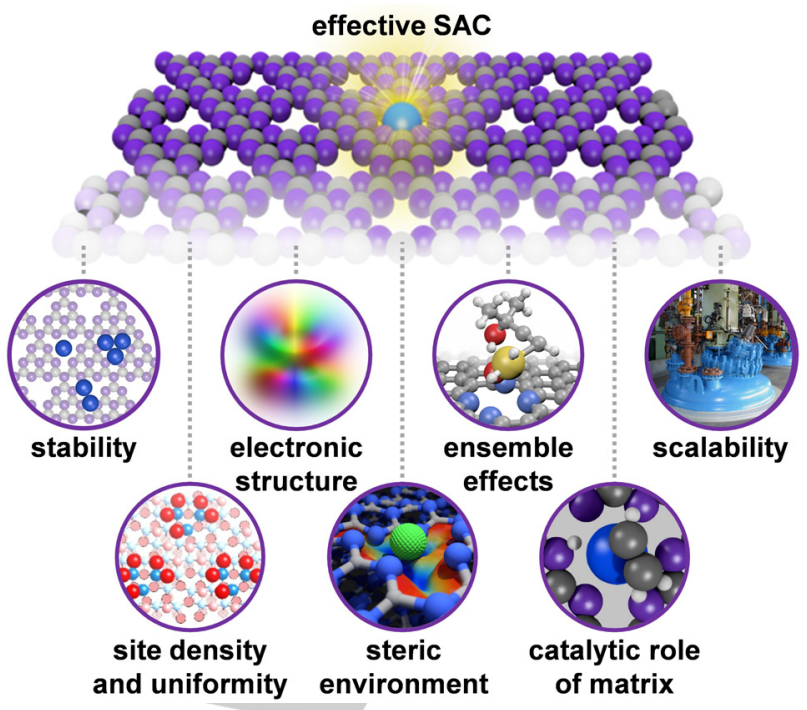

Figure 10. Multiple considerations for the design of a new SAC.

site homogeneity, comparatively few studies have evaluated the relative performance of SACs and homogeneous catalysts. Among those that have addressed this, strong potential to replace soluble metal complexes has been demonstrated, offering possibilities for the implementation of more sustainable catalytic processes. By optimally tailoring the host a similarly high degree of control over the electronic structure and steric environment can be envisaged to that which is now possible through ligand design. The isolation of a metal in an extended matrix has the further advantage that the coordination site remains in close proximity to the active center throughout the catalytic cycle. This offers enhanced stability since it avoids the need to remove ligands, which is also the first step towards deactivation in metal complexes. The use of a host that could adaptively coordinate to the metal was key to surpassing homogeneous catalysts, minimizing the energy requirement in each step.

Sharing some similarities with their heterogeneous and homogeneous ancestors, but also displaying many individual characteristics SACs undoubtedly offer great prospects to explore reactivity in catalysis and reach a similar level of molecular understanding as has been gathered over metal complexes. This review has highlighted multiple design criteria that need to be harmonized to develop an effective SAC (Fig. 10). At this time, few reported systems have been manufactured in large amounts and increased efforts towards scale up will be critical to further demonstrate the technical potential of these pioneering materials.

\section{Acknowledgements}

Financial support by the Swiss National Science Foundation (Grant No. 200021-169679). Sir John M. Thomas, University of Cambridge for multiple inspiring and insightful discussions. 


\section{Conflict of Interest}

The authors declare no conflict of interest.

Keywords: heterogeneous catalysis $\cdot$ homogeneous catalysis • single-atom catalysis $\bullet$ structure-performance relationships $•$ sustainable chemistry

[1] J. M. Thomas, Nat. Catal. 2018, 1, 2; Y. Liang, Y. Li, H. Wang, J. Zhou J, Wang, T. Regier, H. Dai, Nat. Mater. 2011, 10, 780; C. Guo, J. Ran, A. Vasileff, S.-Z. Qiao, Energy Environ. Sci. 2018, 11, 45

[2] J. K. Nørskov, F. Studt, F. Abild-Pedersen, T. Bligaard, Fundamental Concepts in Heterogeneous Catalysis, John Wiley and Sons, Inc. 2003 J. M. Thomas, W. J. Thomas, Principles and Practice of Heterogeneous Catalysis, Wiley-VCH Verlag $\mathrm{GmbH}, 2015$, p. 26.

[3] J. D. Aiken, R. G. Finke, J. Mol. Catal. A: Chem. 1999, 145, 1; L. L. Chng, N. Erathodiyil, J. Y. Ying, Acc. Chem. Res. 2013, 46, 1825.

[4] J. M. Thomas, R. Raja D. W. Lewis, Angew. Chem. Int. Ed. 2005, 44, 6456; Angew. Chem. 2005, 117, 6614; X.-F. Yang, A. Wang, B. Qiao, J. Li, J. Liu, T. Zhang, Acc. Chem. Res. 2013, 46, 1740; W. Zhang, W. Zheng, Adv. Funct. Mater. 2016, 26, 2988; J. Liu, ACS Catal. 2017, 7 34.

[5] C. Zhu, S. Fu, Q. Shi, D. Du, Y. Lin, Angew. Chem. Int. Ed. 2017, 56 13944; Angew. Chem. 2017, 129, 14132; J. Kim, H.-E. Kim, H. Lee, ChemSusChem 2018, 11, 104; H. Zhang, G. Liu, L. Shi, J. Ye, Adv. Energy Mater. 2018, 8, 1701343.

[6] R. A. Sheldon, Chem. Soc. Rev. 2012, 41, 1437.

[7] I. V. Gürsel, T. Noël, Q. Wang, V. Hessel, Green Chem. 2015, 17 2012; S. Hübner, J. G. de Vries, V. Farina, Adv. Synth. Catal. 2016, 358, 3.

[8] L. Liu, A. Corma, Chem. Rev. 2018, 118, 4981.

[9] A. Wang, J. Li, T. Zhang, Nat. Rev. Chem. 2018, 2, 65

[10] M. G. Clerici, U. Romano (Enichem Sintesi SpA, EniTecnologie SpA) EP0230949B1, 1987; A. Corma, L. T. Nemeth, M. Renz, S. Valencia, Nature 2001, 412, 423

[11] B. Qiao, A. Wang, X, Yang, L. F. Allard, Z. Jiang, Y. Cui, J. Liu, J. Li, T. Zhang, Nat. Chem. 2011, 3, 634.

[12] M. Moses-DeBusk, M. Yoon, L. F. Allard, D. R. Mullins, Z. Wu, X. Yang, G. Veith, G. M. Stocks, C. K. Narula, J. Am. Chem. Soc. 2013, 135, 12634.

[13] K. T. Rim, D. Eom, S.-W. Chan, M. Flytzani-Stephanopoulos, G.W. Flynn, X.-D. Wen, E.R. Batista, J. Am. Chem. Soc. 2012, 134 18979.

[14] L. Nie et al. Science 2017, 358, 1419

[15] J. Zhang et al. Nat. Commun. 2018, 9:1002.

[16] J. Zhang, J. Liu, L. Xi, Y. Yu, N. Chen, S. Sun, W. Wang, K. M. Lange, B. Zhang, J. Am. Chem. Soc. 2018, 140, 3876.

[17] M. D. Marcinkowski, M. T. Darby, J. Liu, J. M. Wimble, F. R. Lucci, S Lee, A. Michaelides, M. Flytzani-Stephanopoulos, M. Stamatakis, E. C. H. Sykes, Nat. Chem. 2018, 10, 325

[18] T. Yamada, T. Kojima, E. Abe, S. Kameoka, Y. Murakami, P. Gille, A. P. Tsai, J. Am. Chem. Soc. 2018, 140, 3838.

[19] V. Ortalan, A. Uzun, B. C. Gates, N. D. Browning, Nat. Nanotechnol. 2010, 5, 506.

[20] L. Liu, U. Díaz, R. Arenal, G. Agostini, P. Concepción, A. Corma, Nat. Mater. 2017, 16, 132

[21] T. He, S. Chen, B. Ni, Y. Gong, Z. Wu, L. Song, L. Gu, W. Hu, X. Wang Angew. Chem. Int. Ed. 2018, 57, 3493; Angew. Chem. 2018, 130, 3551

[22] X. Zhang, F. X. L. i Xamena, A. Corma, J. Catal. 2009, 265, 155.

[23] T. Maschmeyer, F. Rey, G. Sankar, J. M. Thomas, Nature 1995, 378, 159

[24] X. Guo et al. Science 2014, 344, 616

[25] H.-J. Qiu, Y. Ito, W. Cong, Y. Tan, P. Liu, A. Hirata, T. Fujita, Z. Tang, M. Chen, Angew. Chem. Int. Ed. 2015, 54, 14031, Angew. Chem. 2015, 127,14237

[26] H. Yan, H. Cheng, H. Yi, Y. Lin, T. Yao, C. Wang, J. Li, S. Wei, J. Lu, J. Am. Chem. Soc. 2015, 137, 10484

[27] Y. Wang, W. Zhang, D. Deng, X. Bao, Chin. J. Catal. 2017, 38, 1443.

[28] C. H. Choi, M. Kim, H. C. Kwon, S. J. Cho, S. Yun, H.-T. Kim, K. J. J. Mayrhofer, H. Kim, M. Choi, Nat. Commun. 2016, 7:10922.
[29] Q. Deng, L. Zhao, X. Gao, M. Zhang, Y. Luo, Y. Zhao, Small 2013, 9, 3506

[30] X. Wang, S. Min, S. K. Das, W. Fan, K.-W. Huang, Z. Lai J. Catal. 2017 $355,101$.

[31] Z. Chen, E. Vorobyeva, S. Mitchell, E. Fako, N López, S.M. Collins, R. K. Leary, P. A. Midgley, R. Hauert, J. Pérez-Ramírez, Natl. Sci. Rev. 2018, doi:10.1093/nsr/nwy048J.

[32] J. Zhao, Z. Chen, J. Am. Chem. Soc. 2017, 139, 12480.

[33] R.-Q. Zhang, T.-H. Lee, B.-D. Yu, C. Stampfl, A. Soon, Phys. Chem. Chem. Phys. 2012, 14, 16552

34] S. Yang, Y. J. Tak, J. Kim, A. Soon, H. Lee, ACS Catal. 2017, 7, 1301

[35] M. Yang, J. Liu, S. Lee, B. Zugic, J. Huang, L. F. Allard, M. FlytzaniStephanopoulos, J. Am. Chem. Soc. 2015, 137, 3470.

[36] M. Yang, S. Li, Y. Wang, J. A. Herron, Y. Xu, L. F. Allard, S. Lee, J. Huang, M. Mavrikakis, M. Flytzani-Stephanopoulos, Science 2014, 346, 1498.

[37] P. Liu et al. Science 2016, 352, 797

[38] G. Kyriakou, M. B. Boucher, A. D. Jewell, E. A. Lewis, T. J. Lawton, A. E. Baber, H. L. Tierney, M. Flytzani-Stephanopoulos, E. C. H. Sykes, Science 2012, 335, 1209.

[39] X. Cao, Q. Fu, Y. Luo, Phys. Chem. Chem. Phys. 2014, 16, 8367.

[40] F. R. Lucci, T. J. Lawton, A. Pronschinske, E. C. H. Sykes, J. Phys. Chem. C 2014, 118, 3015.

[41] R. Lin, S. K. Kaiser, R. Hauert, J. Pérez-Ramírez, ACS Catal. 2018, 8 , 1114

[42] Z. Chen et al. Adv. Funct. Mater. 2017, 27, 1605785

[43] E. Roduner, Chem. Soc. Rev. 2006, 35, 583.

[44] G. X. Pei, X. Y. Liu, X. Yang, L. Zhang, A. Wang, L. Li, H. Wang, X. Wang, T. Zhang, ACS Catal. 2017, 7, 1491.

[45] A. Figueroba, G. Kovács, A. Bruix, K. M. Neyman, Catal. Sci. Technol. 2016, 6, 6806

[46] J. Liang, Q. Yu, X. Yang, T. Zhang, J. Li, Nano Res. 2018, 11, 1599.

[47] E. J. Peterson et al. Nat. Commun. 2014, 5:4885

[48] T. Yang, R. Fukuda, S. Hosokawa, T. Tanaka, S. Sakaki, M. Ehara ChemCatChem 2017, 9, 1222.

[49] E. Fako, Z. Łodziana, N. López, Catal. Sci. Technol. 2017, 7, 4285

[50] Z. Li, T. He, D. Matsumura, S. Miao, A. Wu, L. Liu, G. Wu, P. Chen, ACS Catal. 2017, 7, 6762.

[51] B. Qiao, J.-X. Liang, A. Wang, C.-Q. Xu, J. J. Li, T. Zhang, J. Liu, Nano Res. 2015, 8, 2913.

[52] J. A. Kwon, M.-S. Kim, D. Y. Shin, J. Y. Kim, D.-H. Lim, J. Ind. Eng Chem. 2017, 49, 69.

[53] S. Li, S. Huang, Carbon 2017,115, 11

[54] J. Liu et al. Nat. Commun 2016, 8:15938.

[55] N. Cheng et al. Nat. Commun. 2016, 7:13638.

[56] B. Zhang, H. Asakura, J. Zhang, J. Zhang, S. De, N. Yan, Angew. Chem. Int. Ed. 2016, 55, 8319, Angew. Chem. 2016, 128, 8459.

[57] J. Zhang, A. N. Alexandrova, J. Phys. Chem. Lett. 2013, 4, 2250.

[58] J. L. Shi, X. J. Zhao, L. Y. Zhang, X. L. Xue, Z. X. Guo, Y. F. Gao, S. F. Li, J. Mater. Chem. A 2017, 5, 19316.

[59] J.-C. Liu, Y.-G. Wang, J. Li, J. Am. Chem. Soc. 2017, 139, 6190.

[60] Y. Tang, S. Zhao, B. Long, J.-C. Liu, J. Li, J. Phys. Chem. C 2016, 120, 17514

[61] M.-W. Chang, W.-S. Sheu, Phys. Chem. Chem. Phys. 2016, 18, 15884

[62] S. Ali, T. Liu, Z. Lian, B. Li, D. S. Su, J. Mater. Chem. A 2017, 5, 16653.

[63] R. F. W. Bader, W. H. Henneker, J. Chem. Phys. 1967, 46, 3341.

[64] D. K. Böhme, H. Schwarz, Angew. Chem. Int. Ed. 2005, 44, 2336; Angew. Chem. 2005, 117, 2388.

[65] G. Vilé, D. Albani, M. Nachtegaal, Z. Chen, D. Dontsova, M. Antonietti, N. López, J. Pérez-Ramírez, Angew. Chem. Int. Ed. 2015, 54, 11265; Angew. Chem. 2015, 127, 11417.

[66] Y.-G. Wang, D. Mei, V.-A. Glezakou, J. Li, R. Rousseau, Nat Commun. 2015, 6:6511.

[67] R. Bliem, J. E. S. van der Hoeven, J. Hulva, J. Pavelec, O. Gamba, P. E. de Jongh, M. Schmid, P. Blaha, U. Diebold, G. S. Parkinson, Proc. Natl. Acad. Sci, U. S. A. 2016, 113, 8921; S. Horch, H. T. Lorensen, S. Helveg, E. Lægsgaard, I. Stensgaard, K. W. Jacobsen, J. K. Nørskov, F. Besenbacher, Nature 1999, 398, 134

[68] Z. Chen et al. Nat. Nanotechnol. 2018, doi:10.1038/s41565-018-0167-2.

[69] L. Zhang, A. Wang, J. T. Miller, X. Liu, X. Yang, W. Wang, L. Li, Y. Huang, C.-Y. Mou, T. Zhang, ACS Catal. 2014, 4, 1546.

[70] J. S. Jirkovský, I. Panas, E. Ahlberg, M. Halasa, S. Romani, D. J. Schiffrin, J. Am. Chem. Soc. 2011, 133, 19432. 
[71] H. Wei, X. Liu, A. Wang, L. Zhang, B. Qiao, X. Yang, Y. Huang, S. Miao, J. Liu, T. Zhang, Nat. Commun. 2014, 5:5634.

[72] J. Xi, H. Sun, D. Wang, Z. Zhang, X. Duan, J. Xiao F. Xiao, L. Liu, S. Wang, Appl. Catal., B 2018, 225, 291.

[73] M. D. Rossell, F. J. Caparrós, I. Angurell, G. Muller, J. Llorca, M. Seco, O. Rossell, Catal. Sci. Technol. 2016, 6, 4081.

[74] E. C. Tyo, S. Vajda, Nat. Nanotechnol. 2015, 10, 577

[75] Y. Zhao et al. Proc. Natl. Acad. Sci. U. S. A. 2018, doi:10.1073/pnas.1722137115.

[76] X. Li, W. Zhong, P. Cui, J. Li, J. Jiang, J. Phys. Chem. Lett. 2016, 7, 1750.

[77] Q. Fu, H. Saltsburg, M. Flytzani-Stephanopoulos, Science 2003, 301, 935

[78] M. Flytzani-Stephanopoulos, Acc. Chem. Res. 2014, 47, 783

[79] S. Yao et al. Science 2017, 357, 389.

[80] S. Zhang, J.-J. Shan, Y. Zhu, A. I. Frenkel, A. Patlolla, W. Huang, S. J. Yoon, L. Wang, H. Yoshida, S. Takeda, F. Tao, J. Am. Chem. Soc. 2013, 135, 8283.

[81] K. Ding, A. Gulec, A. M. Johnson, N. M. Schweitzer, G. D. Stucky, L. D. Marks, P. C. Stair, Science 2015, 350, 189.

[82] S. C. Ammal, A. Heyden, ACS Catal. 2017, 7, 301.

[83] Y. Chen, J. Lin, L. Li, B. Qiao, J. Liu, Y. Su, X. Wang, ACS Catal. 2018 $8,859$.

[84] J. Lin, A. Wang, B. Qiao, X. Liu, X. Yang, X. Wang, J. Liang, J. Li, J. Liu T. Zhang, J. Am. Chem. Soc. 2013, 135, 15314.

[85] H. Guan, J. Lin, B. Qiao, S. Miao, A.-Q. Wang, X. Wang, T. Zhang, AIChE J. 2017, 63, 2081

[86] Q. Li, Z. Ma, R. Sa, H. Adidharma, K. A. M. Gasem, A. G. Russell, M. Fan, K. Wu, J. Mater. Chem. A 2017, 5, 14658

[87] M. Valden, X. Lai, D. W. Goodman, Science 1998, 281, 1647.

[88] A. A. Herzing, C. J. Kiely, A. F. Carley, P. Landon, G. J. Hutchings, Science 2008, 321, 1331

[89] M. Haruta, Faraday Discuss. 2011, 152, 11.

[90] L.-W. Guo, P.-P. Du, X.-P. Fu, C. Ma, J. Zeng, R. Si, Y.-Y. Huang C.-J. Jia, Y.-W. Zhang, C.-H. Yan, Nat. Commun. 2016, 7:13481.

[91] B. Qiao, J. Liu, Y.-G. Wang, Q. Lin, X. Liu, A. Wang, J. Li, T. Zhang, J. Liu, ACS Catal. 2015, 5, 6249.

[92] B. Long, Y. Tang, J. Li, Nano Res. 2016, 9, 3868

[93] W. Song, E. J. M. Hensen, J. Phys. Chem. C 2013, 117, 7721.

[94] Y.-G. Wang, D. C. Cantu, M.-S. Lee, J. Li, V.-A. Glezakou, R. Rousseau, J. Am. Chem. Soc. 2016, 138, 10467.

[95] J. Jones et al. Science 2016, 353, 150.

[96] C. Wang, X.-K. Gu, H. Yan, Y. Lin, J. Li, D. Liu, W.-X. Li, J. Lu, ACS Catal. 2017, 7, 887.

[97] A. J. Therrien, A. J. R. Hensley, M. D. Marcinkowski, R. Zhang, F. R. Lucci, B. Coughlin, A. C. Schilling, J.-S. McEwen, E. C. H. Sykes, Nat Catal. 2018, 1, 192

[98] Y. Lou, J. Liu, Ind. Eng. Chem. Res. 2017, 56, 6916.

[99] S. Zhang, C. Chen, M. Cargnello, P. Fornasiero, R. J. Gorte, G. W. Graham, X. Pan, Nat. Commun. 2015, 6:7778.

[100] G. Spezzati, Y. Su, J. P. Hofmann, A. D. Benavidez, A. T. DeLaRiva, J. McCabe, A. K. Datye, E. J. M. Hensen, ACS Catal. 2017, 7, 6887

[101] G. Li, L. Li, D. Jiang, J. Phys. Chem. C 2015, 119, 12502.

[102] J. Liu, B. Liu, Y. Fang, Z. Zhao, Y. Wei, X.-Q. Gong, C. Xu, A. Duan, G. Jiang, Environ. Sci. Technol. 2014, 48, 12403.

[103] Y.-Q. Su, I. A. W. Filot, J.-X. Liu, E. J. M. Hensen, ACS Catal. 2018, 8,

[104] F. Li, Y. Li, X. C. Zeng, Z. Chen, ACS Catal. 2015, 5, 544

[105] X. Wang, Z. Yan, H. Zhou, X. Zhang, J. Jia, H. Wu, Comput. Theor Chem. 2018, 1127, 31.

[106] H. Xu, C.-Q. Xu, D. Cheng, J. Li, Catal. Sci. Technol. 2017, 7, 5860

[107] C. Cheng, X. Zhang, M. Wang, S. Wang, Z. Yang, Phys. Chem. Chem. Phys. 2018, 20, 3504

[108] J.-X. Liang, J. Lin, X.-F. Yang, A.-Q. Wang, B.-T. Qiao, J. Liu, T. Zhang, J. Li, J. Phys. Chem. C 2014, 118, 21945.

[109] X. Zhang, H. Shi, B.-Q. Xu, Angew. Chem. Int. Ed. 2005, 44, 7132; Angew. Chem. 2005, 117, 7294; F. R. Lucci, J. Liu, M. D. Marcinkowski, M. Yang, L. F. Allard, M. Flytzani-Stephanopoulos, E. C. H. Sykes, Nat. Commun. 2015, 6:8550; X. Shi, X. Wang, X. Shang, X. Zou, W. Ding, X Lu, ChemCatChem 2017, 9, 3743; W. Liu, L. Zhang, W. Yan, X. Liu, X. Yang, S. Miao, W. Wang, A. Wang, T. Zhang, Chem. Sci. 2016, 7, 5758.

[110] G. X. Pei, X. Y. Liu, A. Wang, L. Li, Y. Huang, T. Zhang, J. W. Lee, B. W. L. Jang, C.-Y. Mou, New J. Chem. 2014, 38, 2043.
[111] D. Albani, M. Shahrokhi, Z. Chen, S. Mitchell, R. Hauert, N. López, J. Pérez-Ramírez, Nat. Commun. 2018, 9:2634.

[112] E. Vorobyeva, Z. Chen, S. Mitchell, R. K. Leary, P. Midgley, J. M. Thomas, R. Hauert, E. Fako, N. López, J. Pérez-Ramírez, J. Mater. Chem. A 2017, 5, 16393.

[113] G. Malta et al. Science 2017, 355, 1399

[114] M. Tavakkoli, N. Holmberg, R. Kronberg, H. Jiang, J. Sainio, E. I. Kauppinen, T. Kallio, K. Laasonen, ACS Catal. 2017, 7, 3121.

[115] L. Zhang, L. Han, H. Liu, X. Liu, J. Luo, Angew. Chem. Int. Ed. 2017, 56, 13694; Angew. Chem. 2017, 129, 13882.

[116] M. Zhou, J. E. Dick, A. J. Bard, J. Am. Chem. Soc. 2017, 139, 17677.

[117] S. T. Hunt, M. Milina, Z. Wang, Y. Román-Leshkov, Energy Environ. Sci. 2016, 9, 3290.

[118] H. Fei et al. Nat. Commun. 2015, 6:8668.

[119] W. Chen et al. Angew. Chem. Int. Ed. 2017, 56, 16086, Angew. Chem. 2017, 129, 16302

[120] Y. Xue, B. Huang, Y. Yi, Y. Guo, Z. Zuo, Y. Li, Z. Jia, H. Liu, Y. Li, Nat. Commun. 2018, 9:1460

[121] K. Kamiya, R. Kamai, K. Hashimoto, S. Nakanishi, Nat. Commun. 2014, 5:5040.

[122] P. Yin et al. Angew. Chem. Int. Ed. 2016, 55, 10800; Angew. Chem. 2016, 128, 10958

[123] G. Wan et al. Small 2018, 14, 1704319.

[124] Q.-L. Zhu, W. Xia, L.-R. Zheng, R. Zou, Z. Liu, Q. Xu, ACS Energy Lett. 2017, 2, 504

[125] X. X. Wang et al. Adv. Mater. 2018, 30, 1706758

[126] S. Guo, P. Yuan, J. Zhang, P. Jin, H. Sun, K. Lei, X. Pang, Q. Xu, F. Cheng. Chem. Commun. 2017, 53, 9862.

[127] Y.-T. Kim, K. Ohshima, K. Higashimine, T. Uruga, M. Takata, H. Suematsu, T. Mitani, Angew. Chem. Int. Ed. 2006, 45, 407; Angew. Chem. 2006, 118, 421

[128] S. Yang, H. Lee, ACS Catal. 2013, 3, 437

[129] X. Zhang, Z. Sun, B. Wang, Y. Tang, L. Nguyen, Y. Li, F. F. Tao, J. Am. Chem. Soc. 2018, 140, 954.

[130] E.-K. Lee, S.-A. Park, H. Woo, K. H. Park, D. W. Kang, H. Lim, Y.-T. Kim, J. Catal. 2017, 352, 388

[131] L. Duan, R. Fu, Z. Xiao, Q. Zhao, J.-Q. Wang, S. Chen, Y. Wan, ACS Catal. 2015, 5, 575

[132] Y. Liu, Y. Zhou, J. Li, Q. Wang, Q. Qin, W. Zhang, H. Asakura, N. Yan, J. Wang, Appl. Catal., B 2017, 209, 679.

[133] K. Yamaguchi, K. Mori, T. Mizugaki, K. Ebitani, K. Kaneda, J. Am. Chem. Soc. 2000, 122, 7144

[134] S. F. J. Hackett, R. M. Brydson, M. H. Gass, I. Harvey, A. D. Newman, K. Wilson, A. F. Lee, Angew. Chem. Int. Ed. 2007, 46, 8593; Angew. Chem. 2007, 119, 8747.

[135] S. Xie, H. Tsunoyama, W. Kurashige, Y. Negishi, T. Tsukuda, ACS Catal. 2012, 2, 1519

[136] A. Corma et al. Nat. Chem. 2013, 5, 775

[137] S. Ji et al. J. Am. Chem. Soc. 2017, 139, 9795

[138] M. Dhiman, B. Chalke, V. Polshettiwar, J. Mater. Chem. A 2017, 5 , 1935

[139] D. Deng et al. Sci. Adv. 2015; 1:e1500462

[140] J. Xie, K. Yin, A. Serov, K. Artyushkova, H. N. Pham, X. Sang, R. R. Unocic, P. Atanassov, A. K. Datye, R. J. Davis, ChemSusChem 2017, $10,359$.

[141] M. Li, S. Wu, X. Yang, J. Hu, L. Peng, L. Bai, Q. Huo, J. Guan, Appl. Catal. A, Gen. 2017, 543, 61

[142] W. Liu, L. Zhang, X. Liu, X. Liu, X. Yang, S. Miao, W. Wang, A. Wang, T. Zhang, J. Am. Chem. Soc. 2017, 139, 10790.

143] J. Xie et al. ACS Catal. 2018, 8, 3875.

[144] P. Xin et al. Angew. Chem. Int. Ed. 2018, 57, 4642; Angew. Chem. 2018, 130, 4732

[145] C. Li et al. Green Chem. 2016, 18, 2995.

[146] R. Lang et al. Angew. Chem. Int. Ed. 2016, 55, 16054; Angew. Chem. 2016, 128, 16288.

[147] L. Wang et al. Nat. Commun. 2016, 7:14036.

[148] A. J. Therrien, A. J. R. Hensley, M. D. Marcinkowski, R. Zhang, F. R. Lucci, B. Coughlin, A. C. Schilling, J.-S. McEwen, E. C. H. Sykes, Nat. Chem. 2018, 1, 192; C. Paolucci, Science 2017, 357, 898; Yang et al. Nat. Energy 2018, 3, 140 . 


\section{Entry for the Table of Contents}

\section{REVIEW}

Breaking with tradition: By exploring the performance in the reactions studied on single-atom heterogeneous catalysts (SACs), this minireview examines the key factors that may lead to better or worse performance compared to their heterogeneous or homogeneous predecessors based on supported nanoparticles/clusters or metal complexes, showing that SACs almost always exhibit unique catalytic cycles.

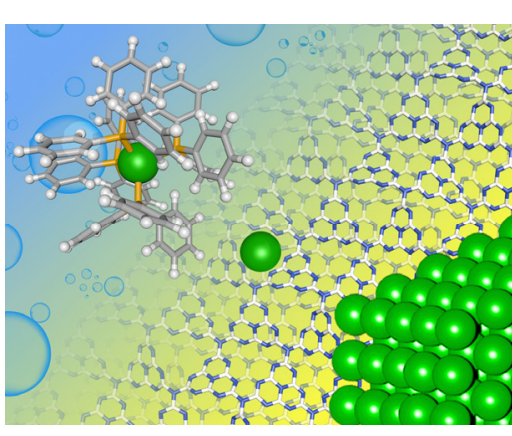

Sharon Mitchell, * Evgeniya Vorobyeva, Javier Pérez-Ramírez*

Page No. - Page No.

Reactivity of Single-Atom Heterogeneous Catalysts: Unique and Multifaceted 